KEYWORDS:

Vadose Flow Vadose Transport Aquifer Transport

RETENTION

Permanent

\title{
PORFLOW Modeling Supporting the H-Tank Farm Performance Assessment
}

\author{
J.M. Jordan \\ G.P. Flach \\ M.L. Westbrook
}

AUGUST 2012

Savannah River National Laboratory Savannah River Nuclear Solutions Savannah River Site Aiken, SC 29808

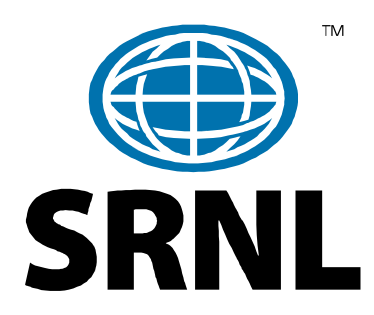




\title{
DISCLAIMER
}

This work was prepared under an agreement with and funded by the U.S. Government. Neither the U. S. Government or its employees, nor any of its contractors, subcontractors or their employees, makes any express or implied:

1. warranty or assumes any legal liability for the accuracy, completeness, or for the use or results of such use of any information, product, or process disclosed; or

2. representation that such use or results of such use would not infringe privately owned rights; or

3. endorsement or recommendation of any specifically identified commercial product, process, or service.

Any views and opinions of authors expressed in this work do not necessarily state or reflect those of the United States Government, or its contractors, or subcontractors.

Printed in the United States of America

Prepared For

\author{
U.S. Department of Energy
}


KEYWORDS:

Vadose Flow Vadose Transport Aquifer Transport

RETENTION

Permanent

\title{
PORFLOW Modeling Supporting the H-Tank Farm Performance Assessment
}

\author{
J.M. Jordan \\ G.P. Flach \\ M.L. Westbrook
}

AUGUST 2012

Savannah River National Laboratory

Savannah River Nuclear Solutions

Savannah River Site

Aiken, SC 29808

Prepared for the U.S. Department of Energy Under

Contract Number DE-AC09-08SR22470 


\section{REVIEWS AND APPROVALS}

DOCUMENT: SRNL-STI-2012-000465, Rev. 0

TITLE: PORFLOW Modeling Supporting the H-Tank Farm Performance Assessment

Date:

J.M. Jordan, Author

SRNL-CSS-ACES

Date:

G.P. Flach, Author

SRNL-ERT-RPA

Date:

M. L. Westbrook, Author

SRNL-CSS-PMMC

Date:

T. Hang, Technical Reviewer

SRNL-CSS-PMMC

Date:

H. H. Burns, Program Manager

SRNL-ERPS

Date:

S.J. Hensel, Manager

SRNL-CSS-CES

Date:

D. A. Crowley, Manager

SRNL-ERT-RPA

Date:

K. H. Rosenberger, C\&WDA

SRR 


\section{TABLE OF CONTENTS}

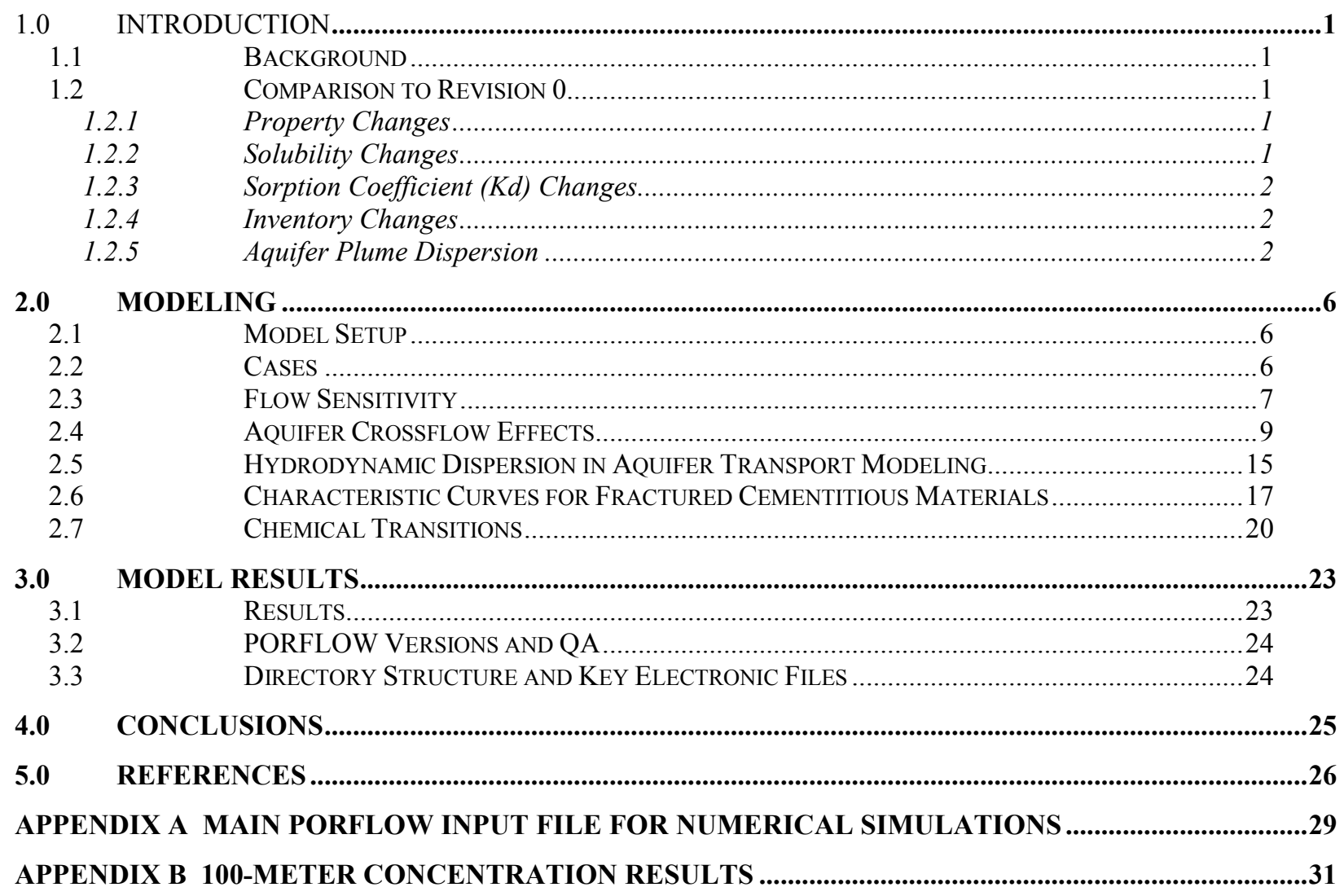


SRNL-STI-2012-00465

\section{LIST OF TABLES}

Table 1 - Tank Grout Fill Properties as represented in the H Tank Farm Performance Assessments................ 1

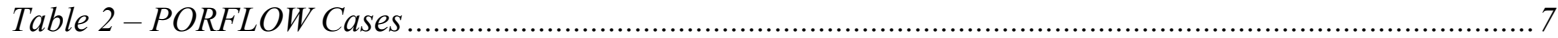

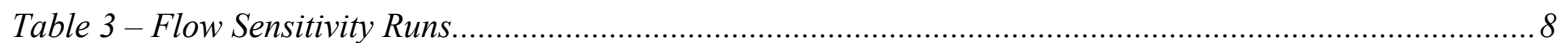

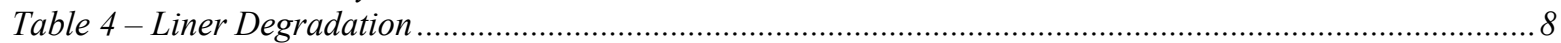

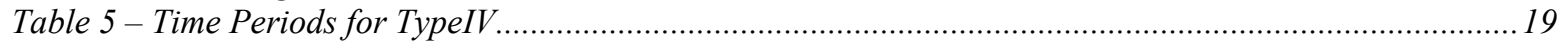

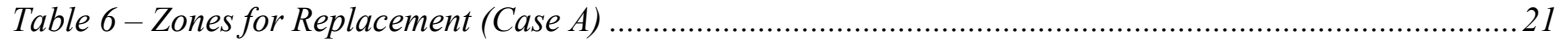

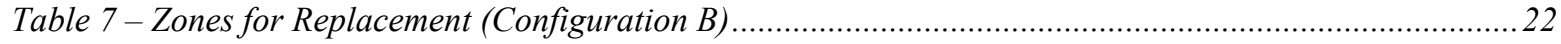

Table 8 - Zones for Replacement (Configuration C) ...........................................................................22

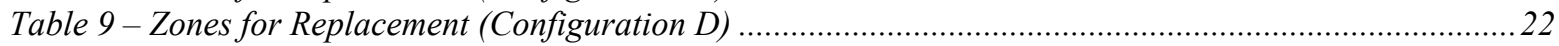

Table 10 - Zones for Replacement (Configuration E) .............................................................................23

\section{LIST OF FIGURES}

Figure 1 - "Fig. 2" from Gelhar et al. (1992) annotated with modeling guidelines for specifying longitudinal dispersivity.

Figure 2 - Comparison of PORFLOW aquifer transport grids for HTF PA (a) Rev. 0 and (b) Rev. 1 .............. 5

Figure 3 - Simulated Aquifer Flow from Portage (2008, Fig. 3-8) with additional annotations..................... 10

Figure 4 - Velocity field results from Portage (2008) "Intact_concrete_cap_liner_690000.sav"file (YZ plane).

Figure 5 - Velocity field results from Portage (2008) "Intact_concrete_cap_liner_690000.sav"file (XZ plane).

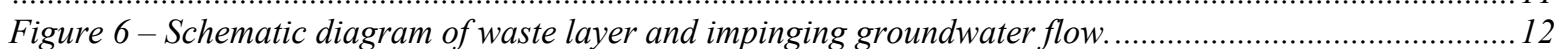

Figure 7 - Numerical simulations of solubility-controlled waste release for varying crossflow. .................... 13

Figure 8 - Impact of crossflow on waste release. ........................................................................... 14

Figure 9 - Grout hydraulic degradation for Type IV tanks in Case A...................................................20 


\subsection{Introduction}

\subsection{Background}

Numerical simulations of groundwater flow and contaminant transport in the vadose and saturated zones have been conducted using the PORFLOW code in support of an overall Performance Assessment (PA) of the H-Tank Farm (SRR, 2012). A general description of the PORFLOW models, and simulation results for several scenarios, are provided in the PA document (e.g. Section 4.4.4.1). This report provides additional technical detail on selected aspects of PORFLOW model development and describes the structure of the associated electronic files.

\subsection{Comparison to Revision 0}

The present PORFLOW modeling supports Revision 1 of the H-Tank Farm PA and is based on the PORFLOW model (SRNL-L6200-2010-00026) that was used for PA Revision 0 (SRR 2011). Some of the input values were changed as discussed in the following sections. These sections also include discussion on the changes that were made to the aquifer model to reduce plume dispersion.

\subsubsection{Property Changes}

The grout properties were changed from the prior work since the tank formulation was modified based upon work conducted by Stefanko and Langton (2011). A comparison of properties is summarized in Table 1. Cementitious materials degrade through time in the same manner as PA Rev. 0 (Watkins 2010).

Table 1 - Tank Grout Fill Properties as represented in the H Tank Farm Performance Assessments

\begin{tabular}{|c|c|c|c|c|c|}
\hline Material & Porosity (\%) & $\begin{array}{l}\text { Dry Bulk Density } \\
\left(\mathrm{g} / \mathrm{cm}^{3}\right)\end{array}$ & $\begin{array}{l}\text { Average Particle } \\
\text { Density }\left(\mathrm{g} / \mathrm{cm}^{3}\right)\end{array}$ & \begin{tabular}{|l} 
Effective \\
Diffusion \\
Coefficient \\
$\left(\mathrm{cm}^{2} / \mathbf{s e c}\right)$ \\
\end{tabular} & \begin{tabular}{|l} 
Saturated \\
Hydraulic \\
Conductivity \\
$(\mathrm{cm} / \mathrm{sec})$
\end{tabular} \\
\hline $\begin{array}{l}\text { Grout Fill from } \\
\text { HTF PA Rev } 0 \\
\end{array}$ & 26.6 & 1.84 & 2.51 & $8.0 \mathrm{E}-07$ & $3.6 \mathrm{E}-08$ \\
\hline $\begin{array}{l}\text { Grout Fill for Rev } \\
\text { HTF PA Rev } 1\end{array}$ & 21.0 & 1.97 & 2.49 & $5.0 \mathrm{E}-08$ & $2.1 \mathrm{E}-09$ \\
\hline
\end{tabular}

\subsubsection{Solubility Changes}

The solubilities used in the modeling were updated for this work. The solubilities are defined in SRNL-STI-2012-00404. The pore volumes required for the Eh-pH transitions were also modified. 
SRNL-STI-2012-00465

\subsubsection{Sorption Coefficient (Kd) Changes}

The $\mathrm{Kd}$ values used in the modeling were updated to the latest values. The values used are defined in SRNL-STI-2009-00473, SRNL-STI-2010-00667, SRNL-STI-2010-00493, SRNLSTI-2010-00527, and SRNL-STI-2011-00672.

\subsubsection{Inventory Changes}

Inventory values were updated for the tanks based on SRR-CWDA-2010-00023, Rev. 3. In addition to the inventory value changes, some inventory was assumed to start in the annulus for the Type I tanks. This inventory was defined to start in a thin zone at the bottom of the annulus.

\subsubsection{Aquifer Plume Dispersion}

Plume spreading in model simulations is influenced by A) physical dispersion (specified by two or more longitudinal and transverse dispersivities), B) numerical dispersion (dependent on the solution algorithm, and spatial and temporal step sizes), and C) heterogeneity in the permeability field. A longitudinal dispersivity of 3.2 meters is specified in Rev. 1 modeling, based on Gelhar et al. (1992) and minimum plume travel distances, as a more conservative assumption in response to concerns about excessive plume spreading.

Gelhar et al. (1992) assembled plume dispersion field data from 59 porous and fractured medium sites (Zheng and Bennett, 1995, Section 9.3.2), with estimates of dispersivity being derived from tracer tests, contamination events, and environmental tracers. Figure 1 includes a reproduction of Figure 2 from Gelhar et al. (1992), which plots longitudinal dispersivity $\left(\alpha_{L}\right)$ against plume scale (L). Also shown in Figure 1 is a common rule of thumb used by practitioners to specify longitudinal dispersivity in contaminant transport models, specifically,

$$
\alpha_{\mathrm{L}}=10^{-1} \mathrm{~L}=0.1 \mathrm{~L}=10 \% \mathrm{~L}
$$

Equation (1) was used to set longitudinal dispersivity in the HTF PA Rev. 0 as shown by the solid line in Figure 1. Equation (1) plots as a straight-line on log-log axes and approximates the trend indicated by the field data. Gelhar et al. (1992) noted that the more reliable dispersivity estimates are biased toward the lower range of the scattered data. Taking into account the data reliability, the practitioner's rule of thumb could possibly be revised as

$$
\alpha_{\mathrm{L}}=10^{-1.5} \mathrm{~L}=0.032 \mathrm{~L}=3.2 \% \mathrm{~L}
$$

which is indicated by the dashed line in Figure 1. Less dispersivity produces larger groundwater concentrations, and Equation (2) is adopted for HTF PA Rev. 1 modeling as a conservative assumption relative to the traditional assumption defined by Equation (1). Because the 100 meter compliance point is measured from the facility perimeter, plume travel distances in the $\mathrm{H}$ Tank Farm range from 100 to a few hundred meters depending on the tank. The minimum travel distance of 100 meters is adopted in Equation (2) as a second conservatism. The longitudinal dispersivity becomes 3.16 meters or 10.4 feet in PORFLOW input. The complete four-parameter 
dispersion model used in HTF PA PORFLOW modeling is presented in Section 2.5. The full set of dispersivities for this model based on Equation (2) are: $\alpha_{\mathrm{LH}}=10.4, \alpha_{\mathrm{TH}}=1.04, \alpha_{\mathrm{LV}}=1.04$, and $\alpha_{\mathrm{TV}}=0.104(\mathrm{ft})$.

The aquifer transport mesh is created by subdividing grid cells in the GSA/PORFLOW aquifer flow model in a cut-out capturing the HTF. In Rev. 0 modeling, each $200 \mathrm{ft}$ by $200 \mathrm{ft}$ GSA/PORFLOW cell in the horizontal plane was divided four ways in each coordinate direction. The vertical resolution was preserved. The aquifer transport grid can be summarized as a "4x4x1" mesh refinement. To minimize numerical dispersion for the longitudinal dispersivity selected for Rev. 1 modeling, the aquifer transport mesh was refined in horizontal plane to a $33 \mathrm{ft}$ x $33 \mathrm{ft}$ resolution (6x6 refinement). Similarly to avoid excessive vertical plume dispersion, the lower aquifer zone (LAZ) was refined by a $2 \mathrm{x}$ factor and the upper grid layer in the Gordon aquifer unit (GAU) was subdivided by $2 \mathrm{x}$. The Rev. 1 refinement is referred to as "6x6xn" refinement, where " $n$ " denotes variable vertical refinement. The longitudinal horizontal numerical dispersion associated with this mesh size is approximately $\alpha_{\text {num }}=D_{\text {num }} / \mathrm{v}=\Delta x / 2=$ $16.7 \mathrm{ft}=5.1 \mathrm{~m}$ (Zheng and Bennett, 1995, Equation 6-45). This result is slightly larger than ideal, but reasonable for average HTF plume travel distances that are well beyond 100 meters. The Rev. 0 and Rev. 1 grids are compared in Figure 2 for an example vertical slice. To allow for variable grid refinement, the MESH3D program, which is used for defining the mesh, was updated. The QA for this program is documented in Q-SQP-G-00003 Rev. 1. 


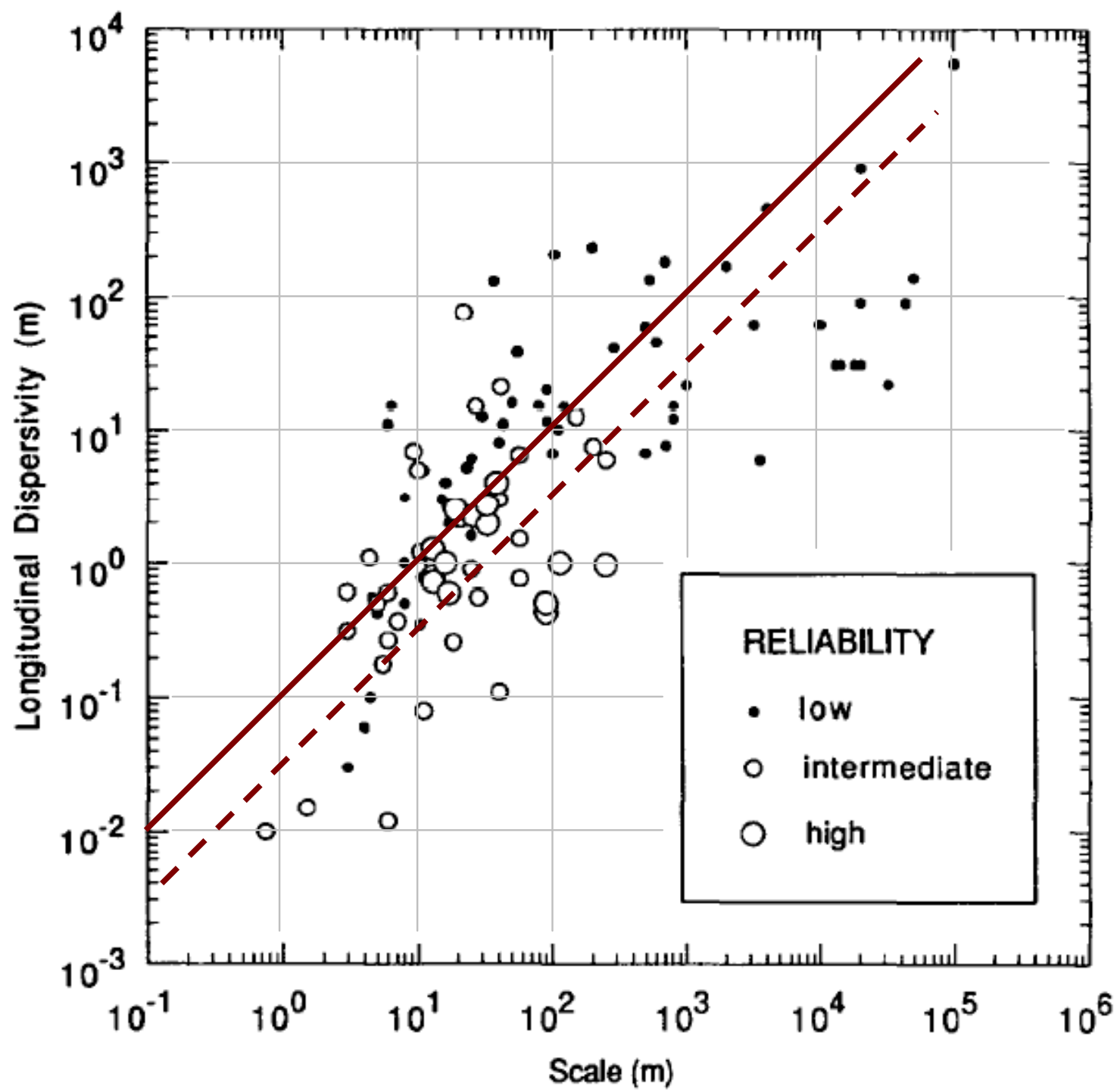

Fig. 2. Longitudinal dispersivity versus scale with data classified by reliability.

Figure 1 - "Fig. 2" from Gelhar et al. (1992) annotated with modeling guidelines for specifying longitudinal dispersivity. 


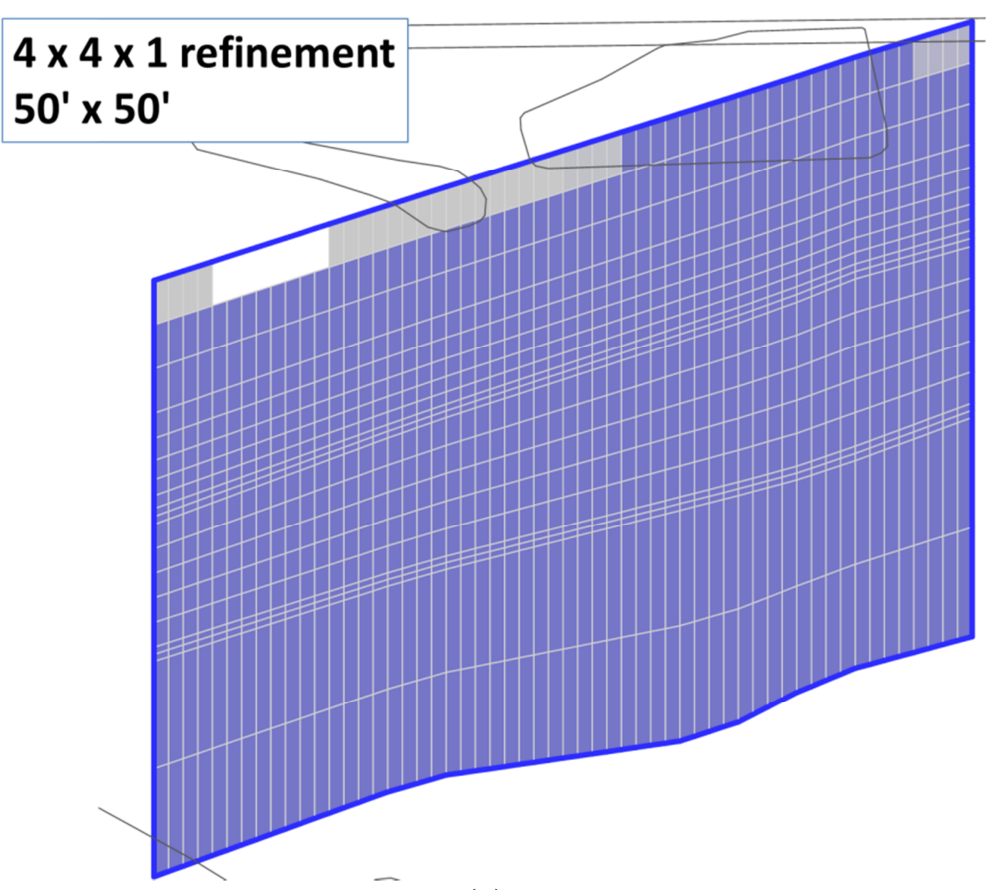

(a)

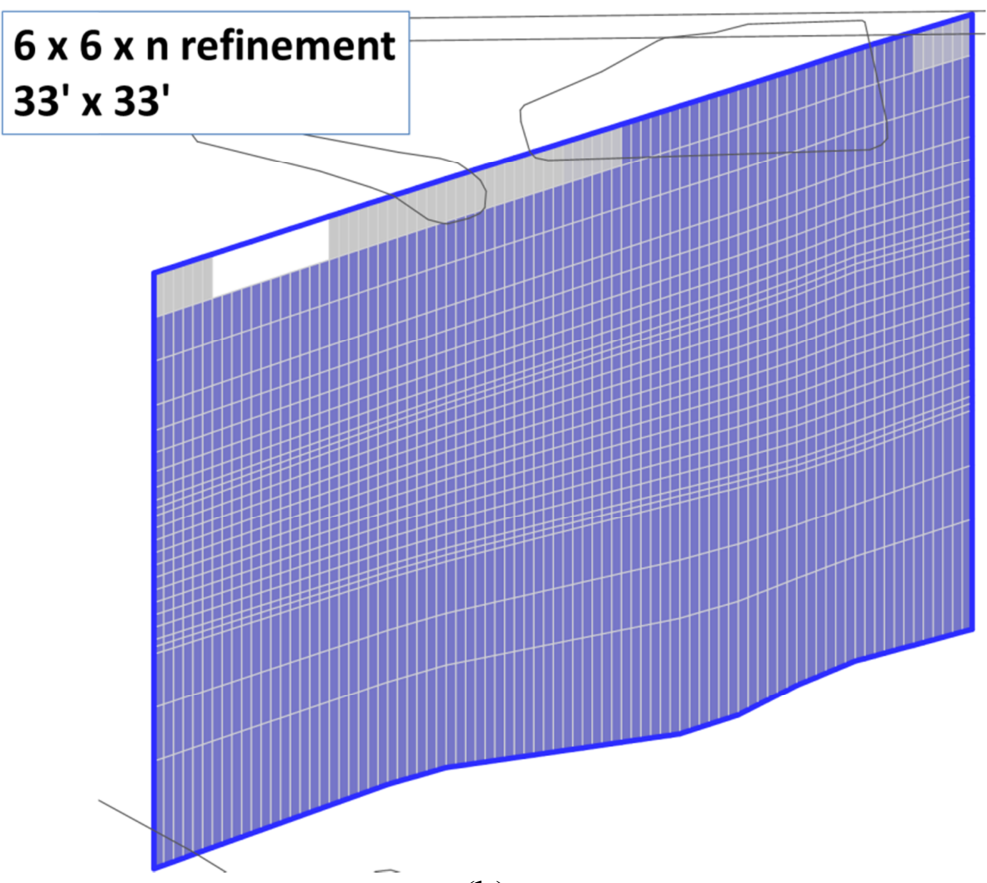

(b)

Figure 2 - Comparison of PORFLOW aquifer transport grids for HTF PA (a) Rev. 0 and (b) Rev. 1. 


\subsection{Modeling}

\subsection{Model Setup}

The general model for Revision 1 of the PA is the same as that for Revision 0. Some properties and input values have changed. The vadose zone model is subdivided based on the type of tank that is being modeled. The tank types found in the H-Tank Farm are TypeI, TypeII, TypeIII, TypeIIIA, and TypeIV. Some of the TypeI and TypeII tanks have degradation of the liner such that the liners were assumed to be failed at time zero. The TypeIIIA tanks are divided in the tank farm, with some having a different depth to the water table. These tanks are divided into TypeIIIA and TypeIIIAWest, with the only difference being the depth to the water table. For the tanks, a total of eight vadose models were run: TypeI, TypeI_noliner, TypeII, TypeII_noliner, TypeIII, TypeIIIA, TypeIIIAWest, and TypeIV.

The ancillary equipment was divided into groups based on their depth to the water table. The process piping was divided into four regions, with different depths to the water table, which were run separately.

\subsection{Cases}

For the H-Tank Farm PA, a series of runs were completed to address different potential conditions. These cases are fully described in the PA, but a brief overview is presented here (Table 2). The expected set of conditions, referred to as the base case, is defined as CaseA within the PORFLOW models. For the CaseA models, a full suite of nuclides and chemicals were modeled for a period of 20,000 years. A smaller subset of key nuclides was defined based on the CaseA results to be used for additional scenarios. 
Table 2 - PORFLOW Cases

\begin{tabular}{|c|c|c|}
\hline Case & Years & Description \\
\hline CaseA_100k & $100 \mathrm{k}$ & CaseA with extended time \\
\hline CaseA - select Tanks & $20 \mathrm{k}$ & $\begin{array}{l}\text { Aquifer results for individual sources instead of all } \\
\text { sources }\end{array}$ \\
\hline CaseB & $100 \mathrm{k}$ & $\begin{array}{l}\text { Partial fast flow path - CZ transition based on grout } \\
\text { transition. }\end{array}$ \\
\hline CaseC & $100 \mathrm{k}$ & Partial fast flow path. \\
\hline CaseD & $100 \mathrm{k}$ & $\begin{array}{l}\text { Full fast flow path }-\mathrm{CZ} \text { transition based on grout } \\
\text { transition. }\end{array}$ \\
\hline CaseE & $100 \mathrm{k}$ & Full fast flow path \\
\hline Case_nocap & $20 \mathrm{k}$ & Fully failed cap from time zero \\
\hline CaseF & $20 \mathrm{k}$ & Synergistic case based on CaseC \\
\hline $\begin{array}{l}\text { CaseA_transition_slow } \\
\text { CaseA_transition_fast }\end{array}$ & $100 \mathrm{k}$ & $\begin{array}{l}\text { CaseA with normal transition times } * 2.0 \\
\text { CaseA with normal transition times*0.5 }\end{array}$ \\
\hline $\begin{array}{l}\text { CaseC_transition_slow } \\
\text { CaseC_transition_fast }\end{array}$ & $100 \mathrm{k}$ & $\begin{array}{l}\text { CaseA with normal transition times*2.0 } \\
\text { CaseA with normal transition times*0.5 }\end{array}$ \\
\hline $\begin{array}{l}\text { CaseA_sol1 } \\
\text { CaseA_sol2 } \\
\text { CaseA_sol3 }\end{array}$ & $100 \mathrm{k}$ & $\begin{array}{l}\text { CaseA different solubilities (Pu-239, Tc-99, Np-237, U- } \\
234 \text { only) }\end{array}$ \\
\hline CaseA_porosity & $20 \mathrm{k}$ & $\begin{array}{l}\text { The effective porosity in the base case (Case A) aquifer } \\
\text { transport simulations is } 25 \% \text {. The porosity sensitivity } \\
\text { case uses one-half of this value, } 12.5 \% \text {. The } \\
\text { corresponding effective solid and bulk densities are } 0.59 \\
\text { and } 0.52 \mathrm{~g} / \mathrm{cm} 3 \text { respectively following Flach }(2012)\end{array}$ \\
\hline $\begin{array}{l}\text { CaseA_kd_half } \\
\text { CaseA_kd_quarter }\end{array}$ & $20 \mathrm{k}$ & $\begin{array}{l}\text { CaseA with aquifer soil } \mathrm{Kd}^{*} 0.5 \\
\text { CaseA with aquifer soil } \mathrm{Kd}^{*} 0.25\end{array}$ \\
\hline $\begin{array}{l}\text { CaseA.1-4 } \\
\text { CaseC.1-4 } \\
\text { CaseE.1-4 } \\
\end{array}$ & $20 \mathrm{k}$ & $\begin{array}{l}\text { Transport runs based on flow sensitivity (described } \\
\text { below) }\end{array}$ \\
\hline $\begin{array}{l}\text { CaseA.3 } \\
\text { CaseA.7 } \\
\text { CaseA.11 }\end{array}$ & $20 \mathrm{k}$ & $\begin{array}{l}\text { Transport runs based on flow sensitivity (described } \\
\text { below) }\end{array}$ \\
\hline
\end{tabular}

\subsection{Flow Sensitivity}

The flow runs from PORFLOW are used in the GoldSim probabilistic models. In order to allow more variability in the GoldSim runs, a series of flow cases were defined as shown in Table 3. These flow runs varied liner failure times, infiltration, and cementitious degradation. Three different starting cases were used, CaseA (no fast flow), CaseC (partial fast flow), and CaseE (full fast flow). In the PORFLOW models, the runs are designated with the starting case followed by the run number, e.g., CaseA.1. 
Table 3 - Flow Sensitivity Runs

\begin{tabular}{|c|c|c|c|}
\hline $\begin{array}{l}\text { Flow } \\
\text { Run }\end{array}$ & $\begin{array}{l}\text { Liner Failure (see } \\
\text { Table 4) }\end{array}$ & $\begin{array}{l}\text { Infiltration Rate } \\
\text { (in/yr) }\end{array}$ & $\begin{array}{l}\text { Hydraulic Conductivity } \\
\text { Curve }\end{array}$ \\
\hline 1 & Zero & Nominal (11.67) & Normal degradation \\
\hline 2 & Early & Nominal (11.67) & Normal degradation \\
\hline 3 & Moderate & Nominal (11.67) & Normal degradation \\
\hline 4 & Late & Nominal (11.67) & Normal degradation \\
\hline 5 & Zero & Nominal (11.67) & Faster degradation \\
\hline 6 & Early & Nominal (11.67) & Faster degradation \\
\hline 7 & Moderate & Nominal (11.67) & Faster degradation \\
\hline 8 & Late & Nominal (11.67) & Faster degradation \\
\hline 9 & Zero & Nominal (11.67) & Slower degradation \\
\hline 10 & Early & Nominal (11.67) & Slower degradation \\
\hline 11 & Moderate & Nominal (11.67) & Slower degradation \\
\hline 12 & Late & Nominal (11.67) & Slower degradation \\
\hline 13 & Zero & No cap $(16.45)$ & Normal degradation \\
\hline 14 & Early & No cap (16.45) & Normal degradation \\
\hline 15 & Moderate & No cap (16.45) & Normal degradation \\
\hline 16 & Late & No cap (16.45) & Normal degradation \\
\hline 17 & Zero & No cap (16.45) & Faster degradation \\
\hline 18 & Early & No cap (16.45) & Faster degradation \\
\hline 19 & Moderate & No cap $(16.45)$ & Faster degradation \\
\hline 20 & Late & No cap (16.45) & Faster degradation \\
\hline 21 & Zero & No cap (16.45) & Slower degradation \\
\hline 22 & Early & No cap (16.45) & Slower degradation \\
\hline 23 & Moderate & No cap (16.45) & Slower degradation \\
\hline 24 & Late & No cap (16.45) & Slower degradation \\
\hline
\end{tabular}

The cementitious degradation was varied by either multiplying or dividing the failure times by 2 . As an example, if a roof was to fail between 400 and 800 years in the normal case, it would fail between 200 and 400 in the fast case and between 800 and 1600 in the slow case. The liner variation times are defined in Table 4.

Table 4 - Liner Degradation

\begin{tabular}{|c|c|c|c|c|c|c|c|c|}
\hline Fast Flow Path: & \multicolumn{4}{|c|}{ None } & \multicolumn{4}{|c|}{ Partial and Full } \\
\hline Label & $\begin{array}{c}\text { Type I } \\
\text { Liner } \\
\text { Failure } \\
\text { Year }\end{array}$ & $\begin{array}{c}\text { Type II } \\
\text { Liner } \\
\text { Failure } \\
\text { Year }\end{array}$ & \begin{tabular}{|c|} 
Type \\
III/IIIA \\
Liner \\
Failure \\
Year \\
\end{tabular} & $\begin{array}{c}\text { Type IV } \\
\text { Liner } \\
\text { Failure } \\
\text { Year }\end{array}$ & $\begin{array}{c}\text { Type I } \\
\text { Liner } \\
\text { Failure } \\
\text { Year }\end{array}$ & $\begin{array}{c}\text { Type II } \\
\text { Liner } \\
\text { Failure } \\
\text { Year }\end{array}$ & \begin{tabular}{|c|} 
Type \\
III/IIIA \\
Liner \\
Failure \\
Year \\
\end{tabular} & \begin{tabular}{|c} 
Type IV \\
Liner \\
Failure \\
Year
\end{tabular} \\
\hline Zero & 0 & 0 & 0 & 0 & 0 & 0 & 0 & 0 \\
\hline Early & 2100 & 2506 & 3100 & 500 & 100 & 100 & 100 & 75 \\
\hline Moderate & 11397 & 12687 & 12751 & 3638 & 1142 & 2506 & 2077 & 1000 \\
\hline Late & 15000 & 14500 & 14500 & 8000 & 11000 & 12000 & 12000 & 3638 \\
\hline
\end{tabular}




\subsection{Aquifer Crossflow Effects}

Type III/IIIA and IV tanks in H-Area reside above the water table and are subject to a downward flow gradient, similar to tanks in F-Area. The resulting axi-symmetric flow around the circular tanks can be efficiently handled by a two-dimensional $(\mathrm{r}, \mathrm{z})$ PORFLOW model. However, Type I tanks are fully submerged and Type II tanks are partially submerged. These tanks may be affected by lateral flow in the saturated zone, in addition to the downward flow component from infiltrating soil moisture. Explicit simulation of aquifer crossflow would require a threedimensional numerical model because conditions are no longer axi-symmetric. The additional computational burden of 3D simulations was judged to be impractical considering the large number of tanks, configurations, scenarios and species to be modeled. Instead, 2D axisymmetric PORFLOW models are used for all tank types, and the effects of aquifer crossflow are accounted for in an approximate manner for Type I and II tanks. Crossflow influences three aspects of PORFLOW simulation, which are discussed in turn below.

When tank steel and concrete components are largely intact and function as the primary barrier to waste release, the main effect of aquifer crossflow is to sweep away contamination that might otherwise build up in soil surrounding the tank, reducing the concentration gradient across the barrier and hindering diffusional releases, if any. Contaminant releases prior to barrier degradation are zero (e.g., prior to liner failure) or small compared to later releases. The effect of any artificial contaminant buildup in PORFLOW simulations is considered insignificant to peak flux results and neglected.

After the primary barrier degrades, advection is the primary release mechanism and crossflow directly contributes to waste release from the contamination zone. However, the relative contribution of the latter can be small or negligible depending on the magnitude of the crossflow and the geometry of the waste zone.

In general, groundwater flow is predominately horizontal in aquifers (and vertical in aquitards), to the extent that vertical flow is often neglected in developing analytic flow solutions. The latter is known as the Dupuit assumption (http://en.wikipedia.org/wiki/Dupuit_assumption, accessed 26 January 2010). However, H-Area tanks reside near a divide in groundwater flow between Fourmile Branch and McQueen Branch / Upper Three Runs. Here the downward flow component is non-negligible compared to lateral flow.

Portage (2008) developed a fully three-dimensional, combined vadose zone and aquifer model of the H-Tank Farm based on a regional scale model of the General Separations Area (Flach 2004). The Portage model provides important insights into the aquifer flow field surrounding submerged tanks in H-Area. Figures 3 through 5, drawn from the work of Portage (2008), illustrate simulated aquifer flow near submerged H-Area tanks. The plots indicate that lateral flows are larger than the downward flow on an absolute basis, but much smaller than the typical aquifer conditions described above, i.e., away from a groundwater divide. A visual survey suggests that horizontal flows do not exceed roughly 10 times the vertical flow. 
Figure 6 is a schematic illustration of the waste layer in an H-Area tank and a representative groundwater velocity vector. Assuming a fixed concentration in the waste zone due to solubility control $\left(\mathrm{c}_{\mathrm{sol}}\right)$, the solute flux exiting the lower surface of the tank is given by

$$
\mathrm{F}_{\mathrm{v}}=\mathrm{c}_{\mathrm{sol}} \mathrm{V} \frac{\pi}{4} \mathrm{D}^{2}
$$

where $\mathrm{V}$ is the vertical component of Darcy velocity, and D is tank diameter. Similarly, the contaminant flux leaving the edge of the waste layer is

$$
\mathrm{F}_{\mathrm{h}}=\mathrm{c}_{\mathrm{sol}} \mathrm{UD} \Delta \mathrm{z}
$$

where $\mathrm{U}$ is the horizontal component of Darcy velocity and $\Delta \mathrm{z}$ is the waste thickness. The ratio of cross to vertical flux is thus

$$
\frac{\mathrm{F}_{\mathrm{h}}}{\mathrm{F}_{\mathrm{V}}}=\frac{\mathrm{c}_{\mathrm{sol}} \mathrm{UD} \Delta \mathrm{z}}{\mathrm{c}_{\mathrm{sol}} \mathrm{V}(\pi / 4) \mathrm{D}^{2}}=\frac{4 \Delta \mathrm{z}}{\pi \mathrm{D}} \frac{\mathrm{U}}{\mathrm{V}} \approx \frac{4 \cdot 0.1^{\prime}}{\pi \cdot 75^{\prime}} \frac{\mathrm{U}}{\mathrm{V}} \approx \frac{1}{600} \frac{\mathrm{U}}{\mathrm{V}}
$$

Equation (5) indicates that the horizontal component of Darcy velocity would have to be 100 times larger than the vertical component for the crossflow flux to become significant because of the geometry of the contamination zone. Figures 3 through 5 indicate lower magnitudes.

\section{group of tanks}

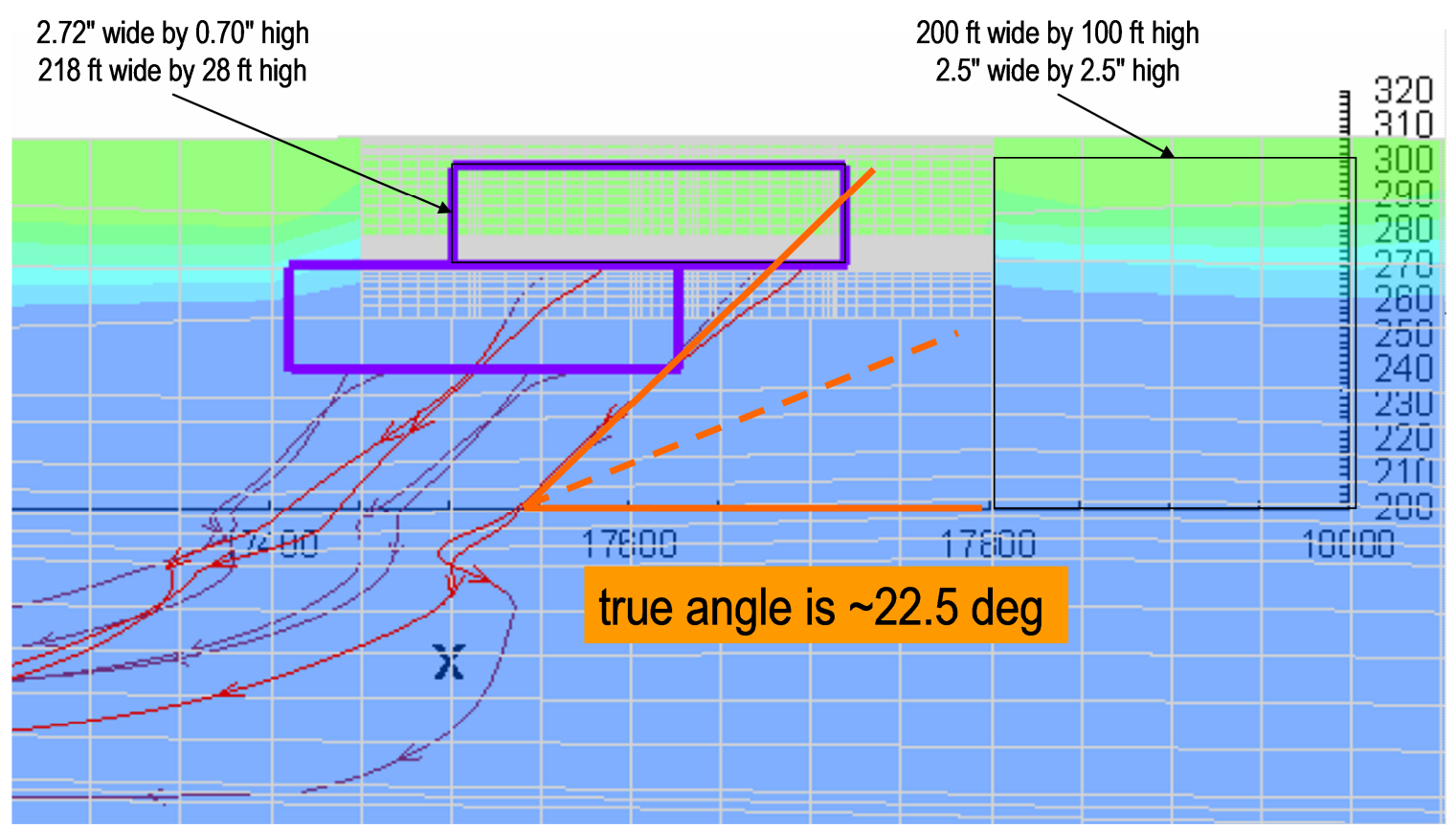

Figure 3 - Simulated Aquifer Flow from Portage (2008, Fig. 3-8) with additional annotations. 


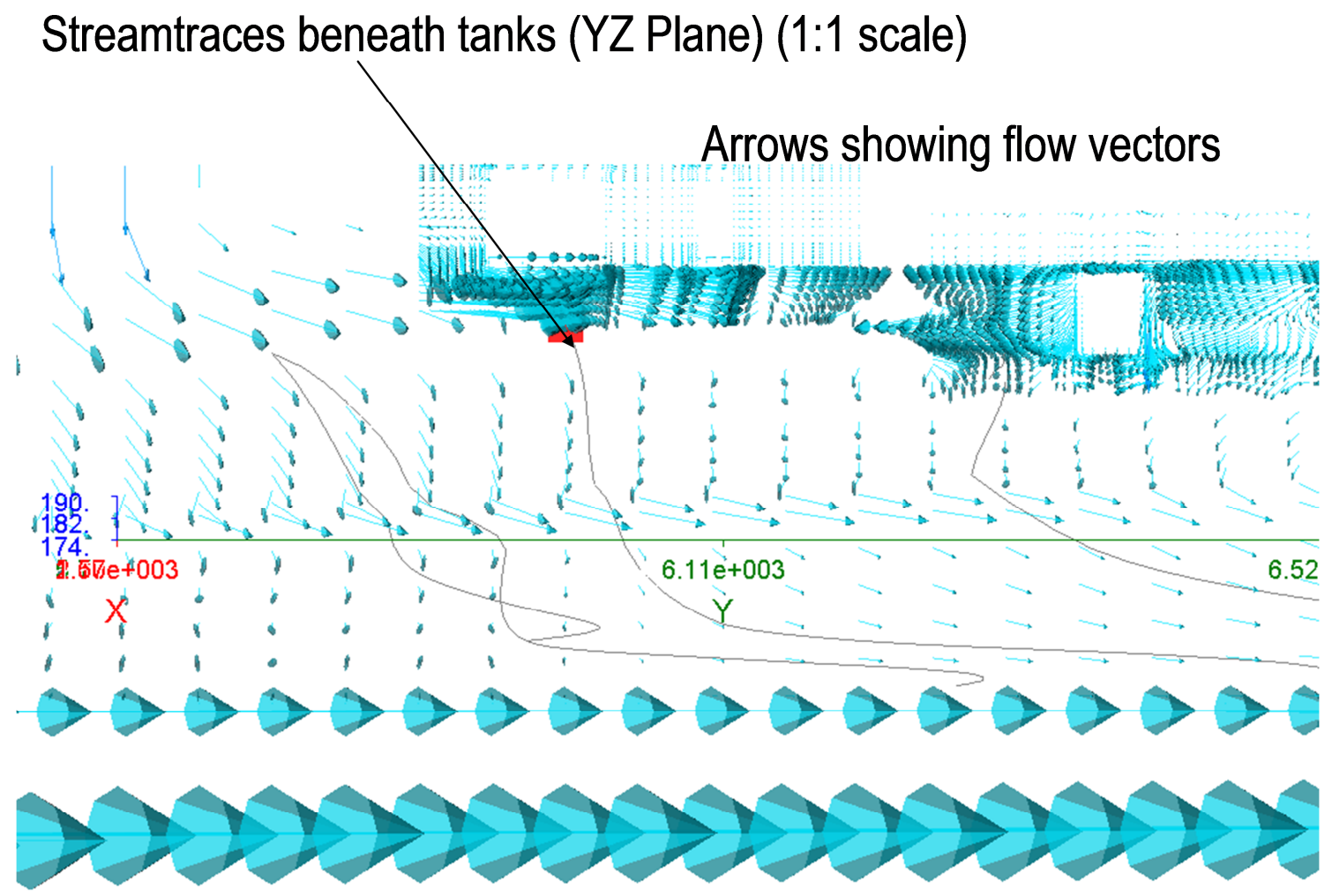

Figure 4 - Velocity field results from Portage (2008)

"Intact_concrete_cap_liner_690000.sav"file (YZ plane).

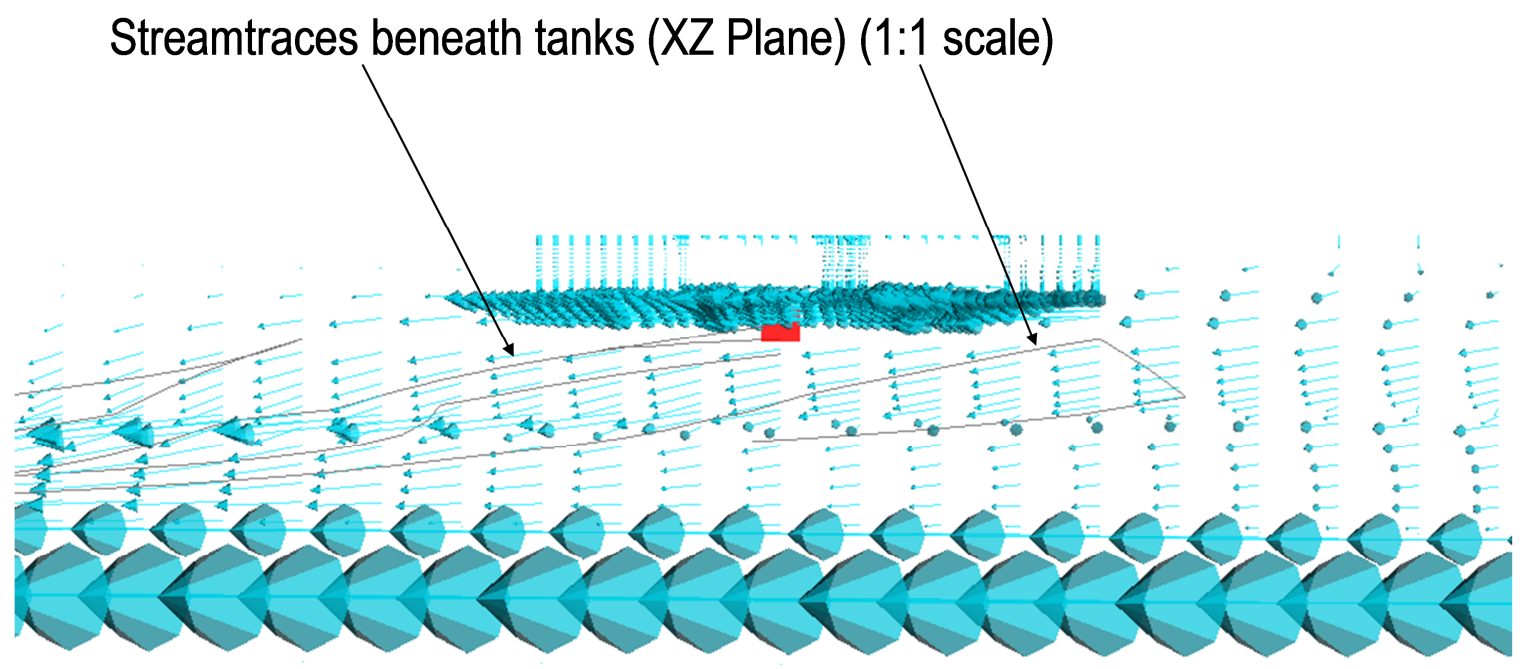

Figure 5 - Velocity field results from Portage (2008)

"Intact_concrete_cap_liner_690000.sav"file (XZ plane). 
Numerical simulations using PORFLOW support the assertion that lateral flows beneath the HTank Farm have minor impact on the overall waste release. Figure 6 shows simulated contaminant release from a $80 \mathrm{ft}$ wide by $0.1 \mathrm{ft}$ thick hypothetical waste layer. The downward flow rate (Darcy velocity) is fixed at $15.85 \mathrm{in} / \mathrm{yr}=40.26 \mathrm{~cm} / \mathrm{s}=1.28 \mathrm{E}-06 \mathrm{~cm} / \mathrm{s}$, which is a representative downward flow through the vadose zone. The crossflow rate is varied from 0 to 1000 times the downward component. The effective diffusion coefficient is set to $5 \mathrm{E}-6 \mathrm{~cm} / \mathrm{s}$. Figure 7 compares the total contaminant release rate to the release rate for no crossflow. The impact of crossflow is observed to be small until the crossflow to downflow ratio exceeds roughly $100 x$, Figure 7 and Figure 8 . Because the crossflow is only on the order of 10x, the impact on the waste layer is minimal. The main PORFLOW input file for these simulations is listed in Appendix A and provides additional detail.

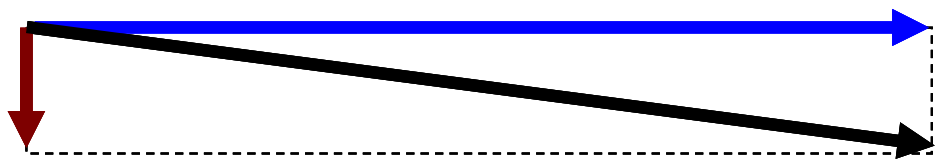

Figure 6 - Schematic diagram of waste layer and impinging groundwater flow. 

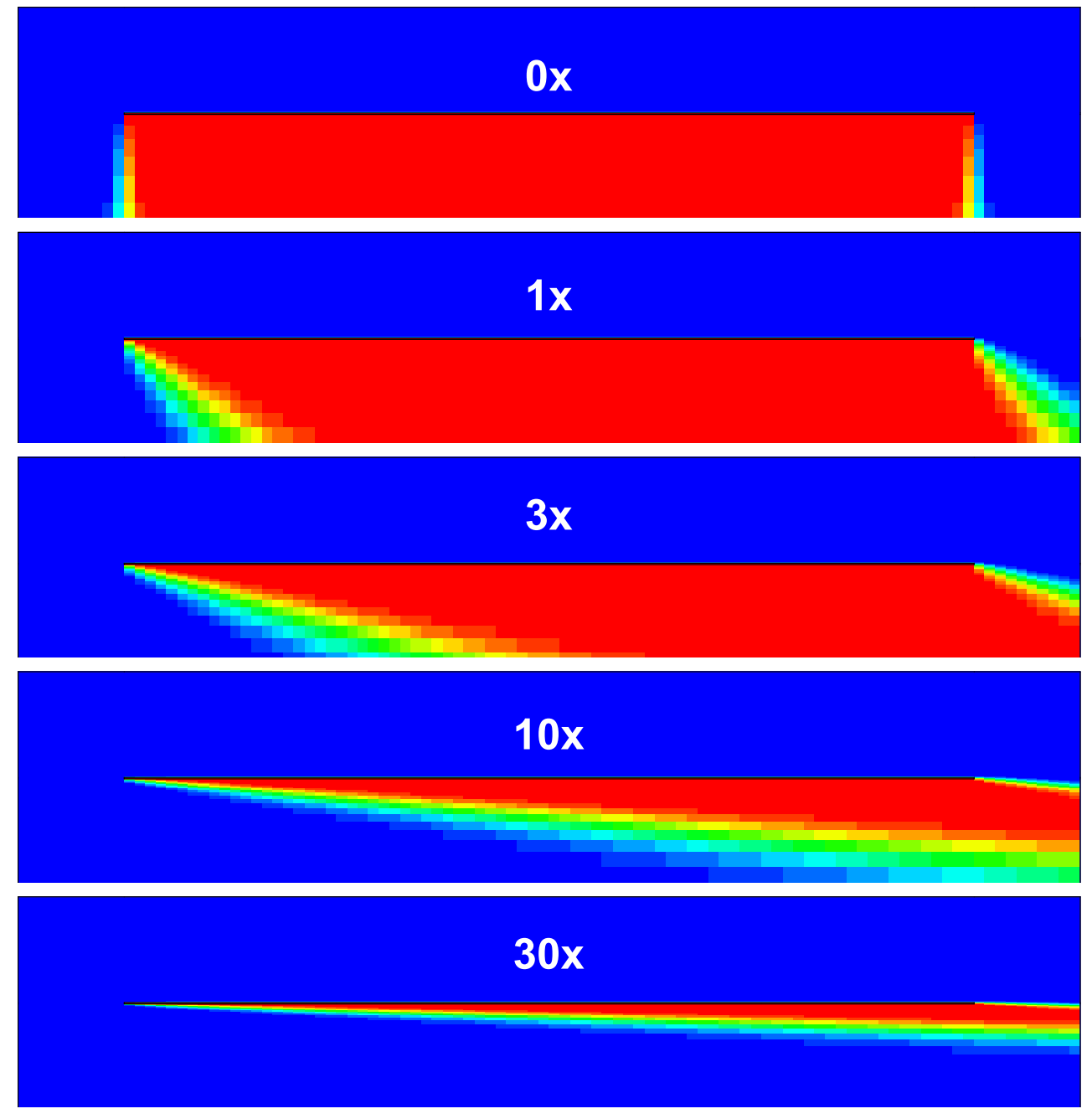

\section{$100 x$}

Figure 7 - Numerical simulations of solubility-controlled waste release for varying crossflow. 


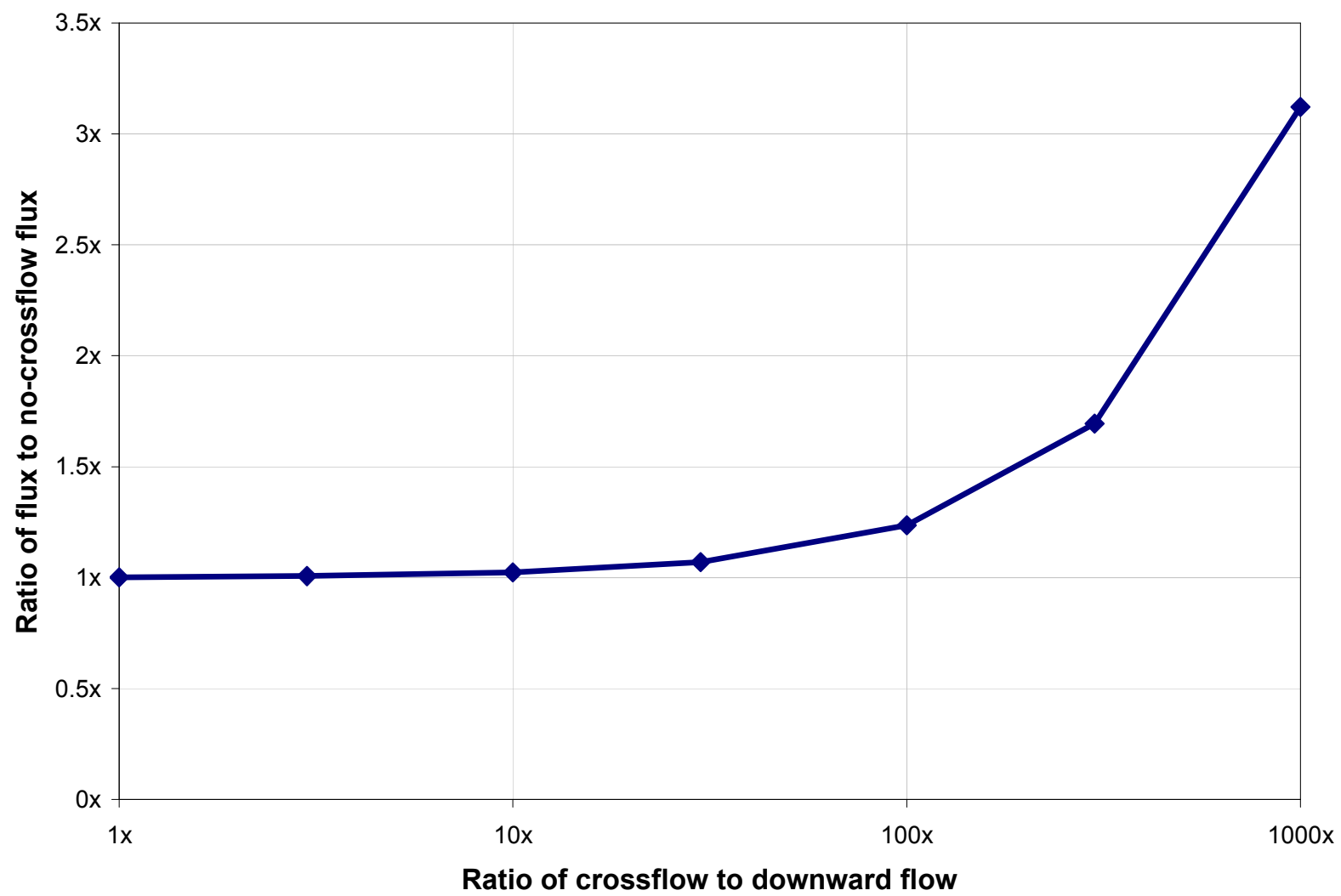

Figure 8 - Impact of crossflow on waste release.

While the thin contamination zone experiences minimal impact from crossflow, thicker components are affected with respect to pore volume flushes and associated chemical transitions. Example features are the tank fill grout and tank wall. Implementation of chemical transitions is discussed in a subsequent section. The increased flow through a region due to combined downflow and crossflow is approximated by the expression

$$
\mathrm{F}=\mathrm{D}\left(1+\frac{\mathrm{C}}{\mathrm{I}}\right)
$$

where $\mathrm{F}$ is total flow, $\mathrm{D}$ is the downward flow component computed by the $2 \mathrm{D}$ axi-symmetric PORFLOW model (which ignores crossflow), $\mathrm{C}$ is the approximate crossflow simulated by Portage (2008), and I is the time-varying infiltration rate. The work of Portage (2008) is based on the GSA/PORFLOW model (Flach 2004), which uses an infiltration rate of $19 \mathrm{in} / \mathrm{yr}$ or 48 $\mathrm{cm} / \mathrm{yr}$. The Portage (2008) crossflow rate is estimated to be 10x the infiltration rate, as discussed earlier, or roughly $480 \mathrm{~cm} / \mathrm{yr}$. Equation (6) defines the flow rate used to calculate pore volume exchanges and corresponding $\mathrm{pH}$ and Eh transitions, which are a function of pore volumes. 


\subsection{Hydrodynamic Dispersion in Aquifer Transport Modeling}

PORFLOW 6.21.0 and earlier versions implement a two-parameter model for hydrodynamic dispersion (e.g., Scheidegger 1961) in terms of longitudinal and transverse dispersivities $\left(\alpha_{\mathrm{L}}, \alpha_{\mathrm{T}}\right)$. The model is best suited to media with isotropic correlation of small-scale hetereogeneity. For a stratified aquifer, the three-parameter Burnett and Frind (1987) model is preferred for groundwater flow parallel to strata (e.g., Zheng and Bennett 1995). Separate transverse horizontal $\left(\alpha_{\mathrm{TH}}\right)$ and transverse vertical $\left(\alpha_{\mathrm{TV}}\right)$ dispersivities enable differential spreading parallel and perpendicular to layering. Hamm and Aleman (2000) proposed a four-parameter generalization of Burnett and Frind (1987) to address situations where flow is perpendicular to strata. The model, implemented in the FACT code (Hamm and Aleman 2000), is defined in terms of longitudinal horizontal $\left(\alpha_{\mathrm{LH}}\right)$, longitudinal vertical $\left(\alpha_{\mathrm{LV}}\right)$, transverse horizontal $\left(\alpha_{\mathrm{TH}}\right)$, and transverse vertical $\left(\alpha_{\mathrm{TV}}\right)$ dispersivities.

The four-parameter Hamm and Aleman (2000) model was recently implemented in PORFLOW version 6.30.2 to enable more accurate simulation of hydrodynamic dispersion in SRS Performance Assessments. PORFLOW version 6.30.2 was selected for HTF aquifer transport modeling in part to enable use of the new "STRAtified" dispersion model, which is further described below. Aleman and Flach (2010) present QA testing results for the STRAtified dispersion option.

The combined solute flux due from diffusion and dispersion is conventionally modeled using Fick's First Law given by

$$
\underline{F}=-\underline{D} \frac{\partial C}{\partial \underline{x}}=-\left[\begin{array}{lll}
D_{x x} & D_{x y} & D_{x z} \\
D_{x y} & D_{y y} & D_{y z} \\
D_{x z} & D_{y z} & D_{z z}
\end{array}\right] \frac{\partial C}{\partial \underline{x}}
$$

where $\underline{F}$ is the composite flux vector, $\mathrm{C}$ is solute concentration, $\underline{\mathrm{x}}$ represents the spatial coordinate vector, and $\underline{\mathrm{D}}$ is the symmetric dispersion/diffusion coefficient tensor ("dispersion coefficients" hereafter). For the four-parameter model of Hamm and Aleman (2000), the dispersion coefficients are defined by

$$
\begin{aligned}
& \mathrm{D}_{\mathrm{xx}}=\alpha_{\mathrm{LH}} \frac{\mathrm{v}_{\mathrm{x}}^{2}}{|\underline{\mathrm{v}}|}+\alpha_{\mathrm{TH}} \frac{\mathrm{v}_{\mathrm{y}}^{2}}{|\underline{\mathrm{v}}|}+\alpha_{\mathrm{TV}} \frac{\mathrm{v}_{\mathrm{z}}^{2}}{|\underline{\mathrm{v}}|}+\mathrm{D}^{*} \\
& \mathrm{D}_{\mathrm{yy}}=\alpha_{\mathrm{TH}} \frac{\mathrm{v}_{\mathrm{x}}^{2}}{|\underline{\mathrm{v}}|}+\alpha_{\mathrm{LH}} \frac{\mathrm{v}_{\mathrm{y}}^{2}}{|\underline{\mathrm{v}}|}+\alpha_{\mathrm{TV}} \frac{\mathrm{v}_{\mathrm{z}}^{2}}{|\underline{\mathrm{v}}|}+\mathrm{D}^{*} \\
& \mathrm{D}_{\mathrm{zz}}=\alpha_{\mathrm{TV}} \frac{\mathrm{v}_{\mathrm{x}}^{2}}{|\underline{\mathrm{v}}|}+\alpha_{\mathrm{TV}} \frac{\mathrm{v}_{\mathrm{y}}^{2}}{|\underline{\mathrm{v}}|}+\alpha_{\mathrm{LV}} \frac{\mathrm{v}_{\mathrm{z}}^{2}}{|\underline{\mathrm{v}}|}+\mathrm{D}^{*}
\end{aligned}
$$




$$
\begin{aligned}
& \mathrm{D}_{\mathrm{xy}}=\left(\alpha_{\mathrm{LH}}-\alpha_{\mathrm{TH}}\right) \frac{\mathrm{v}_{\mathrm{x}} \mathrm{v}_{\mathrm{y}}}{|\underline{\mathrm{v}}|} \\
& \mathrm{D}_{\mathrm{xz}}=\left(\hat{\alpha}_{\mathrm{L}}-\alpha_{\mathrm{TV}}\right) \frac{\mathrm{v}_{\mathrm{x}} \mathrm{v}_{\mathrm{z}}}{|\underline{\mathrm{v}}|} \\
& \mathrm{D}_{\mathrm{yz}}=\left(\hat{\alpha}_{\mathrm{L}}-\alpha_{\mathrm{TV}}\right) \frac{\mathrm{v}_{\mathrm{y}} \mathrm{v}_{\mathrm{z}}}{|\underline{\mathrm{v}}|}
\end{aligned}
$$

where

$$
\hat{\alpha}_{L}=\frac{\alpha_{L H}+\alpha_{L V}}{2}
$$

$\underline{\mathrm{v}}$ is pore velocity, $\mathrm{D}^{*}$ is the effective molecular diffusion coefficient, and $\alpha_{\mathrm{LH}}, \alpha_{\mathrm{LV}}, \alpha_{\mathrm{TH}}$, and $\alpha_{\mathrm{TV}}$ are longitudinal horizontal, longitudinal vertical, transverse horizontal, and transverse vertical dispersivities.

Flach (2009) summarizes guidelines for assigning values to these parameters from Zheng and Bennett (1995) for the special case of flow parallel to strata (Burnett and Frind (1987) model), namely,

$$
\begin{gathered}
\alpha_{\mathrm{L}(\mathrm{H})}=10 \% \mathrm{~L} \\
\alpha_{\mathrm{TH}}=1 \% \mathrm{~L}=10 \% \alpha_{\mathrm{L}} \\
\alpha_{\mathrm{TV}}=0.1 \% \mathrm{~L}=1 \% \alpha_{\mathrm{L}}=10 \% \alpha_{\mathrm{TH}}
\end{gathered}
$$

where $\mathrm{L}$ is the plume length scale. For flow perpendicular to strata, a reasonable assignment is

$$
\alpha_{\mathrm{LV}}=1 \% \mathrm{~L}
$$

considering a lower potential for differential velocities. For Revision 1 modeling, as discussed in Section 1.2.5, the guidelines of Zheng and Bennett (1995) are revised downward to

$$
\begin{gathered}
\alpha_{\mathrm{L}(\mathrm{H})}=3.16 \% \mathrm{~L} \\
\alpha_{\mathrm{TH}}=0.316 \% \mathrm{~L}=10 \% \alpha_{\mathrm{L}} \\
\alpha_{\mathrm{TV}}=0.0316 \% \mathrm{~L}=0.316 \% \alpha_{\mathrm{L}}=10 \% \alpha_{\mathrm{TH}}
\end{gathered}
$$




$$
\alpha_{L V}=0.316 \% \mathrm{~L}
$$

where the ratios between dispersivities and length scale (L) are preserved relative to Revision 0 . The corresponding dispersivities chosen for HTF aquifer transport modeling are thus $\alpha_{\mathrm{LH}}=10.4$, $\alpha_{\mathrm{TH}}=1.04, \alpha_{\mathrm{LV}}=1.04$, and $\alpha_{\mathrm{TV}}=0.104 \mathrm{ft}$.

\subsection{Characteristic Curves for Fractured Cementitious Materials}

In the H-Tank Farm Performance Assessment concrete and grout are assumed to exist as intact matrices initially, and then physically degrade over time (Watkins 2010) through cracking. Saturated conductivity and characteristic curves are modified through time by blending matrix and fracture properties, following the approach described for Saltstone PA modeling (Flach et al. 2009, section 3.7). The method for degrading materials through time is presented here.

Method: The hydraulic properties of the fractures are estimated from Or and Tuller (2000) for a specified aperture (b) and surface roughness parameter (L). The properties of the intact matrix are taken from WSRC-STI-2006-00198, Rev. 0 (Phifer et al. 2006). The equivalent hydraulic properties of the fractured matrix are then derived by blending the fracture and matrix properties for a prescribed fracture spacing (B) that varies with time according to log-linear relationship

$$
\log 10(\mathrm{~B})=\left\{\begin{array}{cc}
\infty & \mathrm{t} \leq \mathrm{t}_{0 \%} \\
\frac{\log 10\left(\mathrm{~B}_{100 \%}\right)-\log 10\left(\mathrm{~B}_{0 \%}\right)}{\log 10\left(\mathrm{t}_{100 \%}\right)-\log 10\left(\mathrm{t}_{0 \%}\right)}\left[\log 10(\mathrm{t})-\log 10\left(\mathrm{t}_{0 \%}\right)\right]+\log 10\left(\mathrm{~B}_{0 \%}\right) & \mathrm{t}_{0 \%}<\mathrm{t}<\mathrm{t}_{100 \%} \\
\log 10\left(\mathrm{~B}_{100 \%}\right) & \mathrm{t} \geq \mathrm{t}_{100 \%}
\end{array}\right.
$$

where $t$ is elapsed time and the subscripts refer to $0 \%$ and $100 \%$ degradation. The evaluation time is defined as the midpoint of the flow simulation period in log-space, i.e.,

$$
\log 10(\mathrm{t})=0.5\left[\log 10\left(\mathrm{t}_{\mathrm{TI}-}\right)+\log 10\left(\mathrm{t}_{\mathrm{TI}+}\right)\right]
$$

where $\mathrm{t}_{\mathrm{TI}}$ and $\mathrm{t}_{\mathrm{TI}}$ are the start and end times of the flow time interval (TI). The blended (equivalent) properties of the degraded material are defined by

$$
\begin{gathered}
\mathrm{K}=\frac{\mathrm{bK}_{\mathrm{f}}+B K_{m}}{\mathrm{~b}+\mathrm{B}} \\
\mathrm{n}=\frac{\mathrm{bn}_{\mathrm{f}}+B n_{m}}{\mathrm{~b}+\mathrm{B}} \\
\mathrm{S}=\frac{\mathrm{bn}_{\mathrm{f}} \mathrm{S}_{\mathrm{f}}+B \mathrm{Bn}_{\mathrm{m}} \mathrm{S}_{\mathrm{m}}}{(\mathrm{b}+\mathrm{B}) \mathrm{n}}
\end{gathered}
$$




$$
\begin{gathered}
\mathrm{k}_{\mathrm{r}}=\frac{\mathrm{bk}_{\mathrm{rf}} \mathrm{K}_{\mathrm{f}}+\mathrm{Bk}_{\mathrm{rm}} \mathrm{K}_{\mathrm{m}}}{(\mathrm{b}+\mathrm{B}) \mathrm{K}} \\
\mathrm{K}_{\text {unsat }}=\mathrm{k}_{\mathrm{r}} \mathrm{K}
\end{gathered}
$$

Parameter settings: The start and end times for degradation are taken from Table 1 in SRRCWDA-2010-00019 and depend on tank type (Watkins 2010).

The fracture spacings $\mathrm{B}_{0 \%}$ and $\mathrm{B}_{100 \%}$ are chosen to be 10,000 meters $(10 \mathrm{~km})$ and 0.1 meters (10 $\mathrm{cm}$ ), respectively. A spacing of $10 \mathrm{~km}$ is practically equivalent to an infinite spacing, or an undegraded matrix. A spacing of $10 \mathrm{~cm}$ (4 in) corresponds to dense cracking, consistent with the concept of complete physical degradation.

The fracture aperture is chosen to be $b=0.005 \mathrm{in}=0.127 \mathrm{~mm}$, which is characteristic of microcracking. The pit depth (Or and Tuller 2000) is set to $\mathrm{L}=0.050 \mathrm{~mm}$, which corresponds to a rough fracture face.

The saturated properties of intact material are taken from WSRC-STI-2007-00369 (Dixon and Phifer 2007) and Table 1. The characteristic curves for unsaturated conditions are assumed to be those of high quality concrete in WSRC-STI-2006-00198 (Phifer et al. 2006). The specific properties are defined in .../Common/config and listed here:

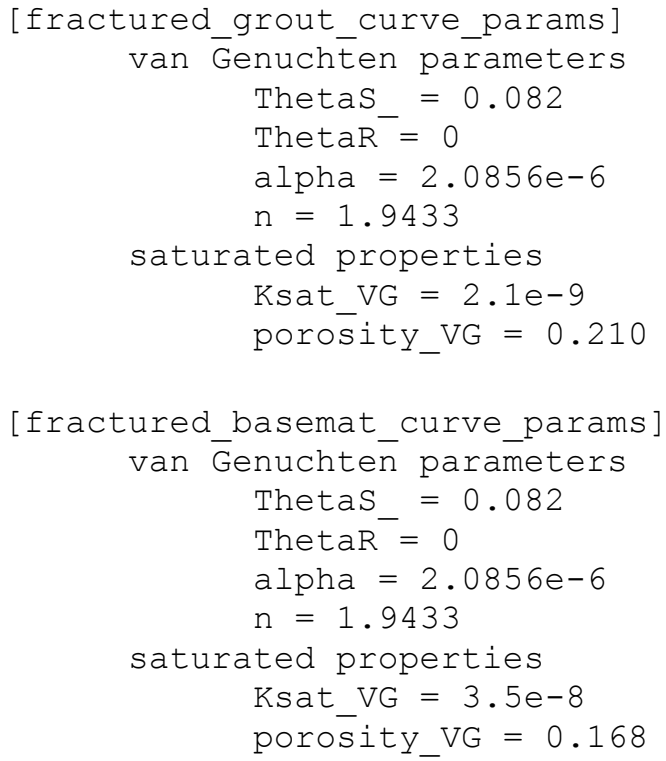

Example: The tank fill grout in Type IV tanks is modeled as degrading over the period from 800 to 64,400 years. Figure 9 illustrates how unsaturated hydraulic conductivity varies as a function of suction head for selected time intervals, which are specified in Table 5. 
Table 5 - Time Periods for TypeIV

\begin{tabular}{|l|l|l|}
\hline Period & Start_yr & End_yr \\
\hline TI01 & 0 & 75 \\
\hline TI02 & 75 & 100 \\
\hline TI03 & 100 & 200 \\
\hline TI04 & 200 & 300 \\
\hline TI05 & 300 & 400 \\
\hline TI06 & 400 & 500 \\
\hline TI07 & 500 & 600 \\
\hline TI08 & 600 & 800 \\
\hline TI09 & 800 & 1000 \\
\hline TI10 & 1000 & 1200 \\
\hline TI11 & 1200 & 1400 \\
\hline TI12 & 1400 & 1700 \\
\hline TI13 & 1700 & 2077 \\
\hline TI14 & 2077 & 2300 \\
\hline TI15 & 2300 & 2550 \\
\hline TI16 & 2550 & 2700 \\
\hline TI17 & 2700 & 3200 \\
\hline TI18 & 3200 & 3638 \\
\hline TI19 & 3638 & 4000 \\
\hline TI20 & 4000 & 4500 \\
\hline TI21 & 4500 & 5000 \\
\hline TI22 & 5000 & 5500 \\
\hline TI23 & 5500 & 6000 \\
\hline TI24 & 6000 & 6500 \\
\hline TI25 & 6500 & 7000 \\
\hline TI26 & 7000 & 8000 \\
\hline TI27 & 8000 & 8500 \\
\hline TI28 & 8500 & 9000 \\
\hline TI29 & 9000 & 9500 \\
\hline TI30 & 9500 & 10000 \\
\hline TI31 & 10000 & 11000 \\
\hline TI32 & 11000 & 12000 \\
\hline TI33 & 12000 & 13200 \\
\hline TI34 & 13200 & 14000 \\
\hline TI35 & 14000 & 15000 \\
\hline TI36 & 15000 & 16000 \\
\hline TI37 & 16000 & 17500 \\
\hline TI38 & 17500 & 20000 \\
\hline TI39 & 20000 & 64400 \\
\hline TI40 & 64400 & 100000 \\
\hline & & \\
\hline
\end{tabular}


Cracking is observed to have a strong influence on hydraulic conductivity for low suctions, but a negligible effect for suctions greater than $100 \mathrm{~cm}$.

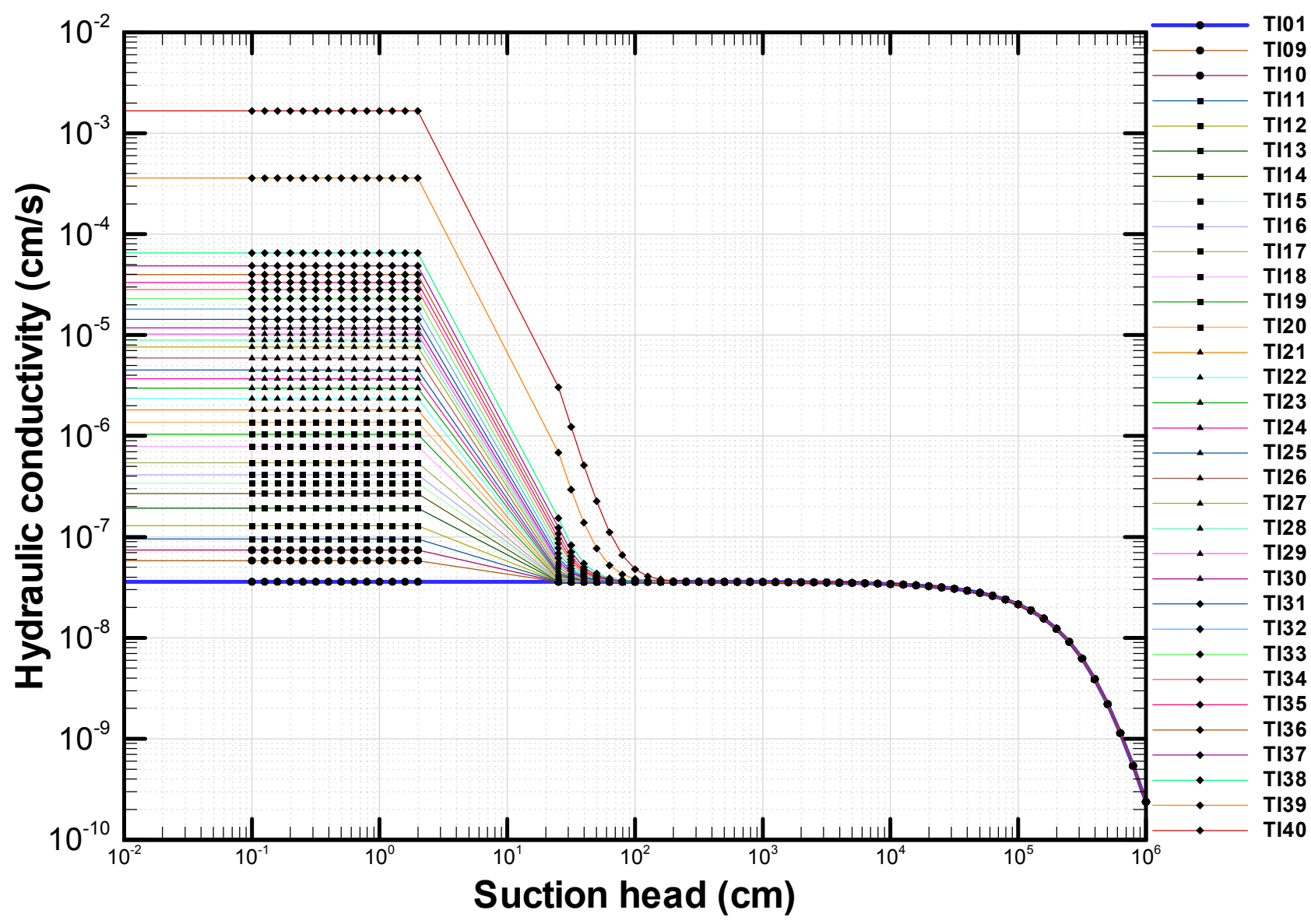

Figure 9 - Grout hydraulic degradation for Type IV tanks in Case A.

\subsection{Chemical Transitions}

In PORFLOW modeling, infiltrate pore volume as a function of time is calculated outside of PORFLOW after flow simulations have been completed. Chemical transitions in subsequent transport modeling are based on these calculations, and $\mathrm{E}_{\mathrm{h}}$ and $\mathrm{pH}$ transitions as a function of pore volumes from WSRC-STI-2007-00544 Rev. 2 (Denham 2010).

The pore volume transitions are different depending on whether or not the pore water is assumed to be ground water. For the tanks which are below grade, the pore water is assumed to be ground water and the transition volumes are those associated with that condition. From an application stand-point, when the cross-flow factor (Equation 6) is applied, the pore volume transitions are those for the submerged condition. Further details on the implementation of the cross-flow factor are described below. 
Conceptually, chemical transitions for a zone are based on the pore volume count for that zone. However, some of the material zones have portions that have very different flow rates from the bulk of the material. For some materials and cases, chemical transitions for a particular zone are tied to the transition in another zone. For example, the basemat of Type II tanks is divided into three sub-zones: 1) a thicker disk at the tank centerline - identified as FF_BASEMAT, 2) an outer ring beneath the annulus space - identified as BASEMAT_NON_PORE, and 3) the remaining center ring - identified as BASEMAT. The transition times for all three regions are tied to the pore volume count through the center ring. Thus no credit is taken for the thicker inner disk, nor is the pore volume count biased by faster flows rounding the outside corner of the overall basemat. For those regions, which are not representative of the bulk of the material, the transition times are based on the core section and applied to these outer regions. For the base case, Table 6 identifies each zone that does not get chemical transitions based on the flow through that same zone.

Table 6 - Zones for Replacement (Case A)

\begin{tabular}{|l|l|}
\hline Material Zone & Zone For Transition \\
\hline BASE_NON_PORE & BASEMAT \\
\hline ROOF_NON_PORE & ROOF \\
\hline WALL_NON_PORE & WALL \\
\hline CENTER_RISER & ROOF \\
\hline DOME_RING & ROOF \\
\hline CONTAM_ZONE & TANK_GROUT \\
\hline FF_TANK_GROUT & TANK_GROUT \\
\hline FF_BASEMAT & BASEMAT \\
\hline FF_ROOF & ROOF \\
\hline
\end{tabular}

The other zone of note in the above table is the very thin CZ (CONTAM_ZONE). In the base configuration, infiltrate flows downward through the tank fill grout and the pore water chemistry of the overlying grout is assumed to be imparted on the very thin $\mathrm{CZ}$ in intimate contact with grout. Therefore, the chemical transition times are considered to be identical for the two materials.

For fast-flow configurations, when a fast-flow path is active, it has no chemical transitions. These zones are then ignored for the pore volume calculation. For Configuration B with a fastflow path through the roof and grout, but not through the basemat, the replacement zones are updated as indicated in Table 7. 
Table 7 - Zones for Replacement (Configuration B)

\begin{tabular}{|l|l|}
\hline Material Zone & Zone For Transition \\
\hline BASE_NON_PORE & BASEMAT \\
\hline ROOF_NON_PORE & ROOF \\
\hline WALL_NON_PORE & WALL \\
\hline CENTER_RISER & ROOF \\
\hline DOME_RING & ROOF \\
\hline CONTAM_ZONE & TANK_GROUT \\
\hline FF_BASEMAT & BASEMAT \\
\hline
\end{tabular}

For the $\mathrm{CZ}$, a fast flow path around the grout exists initially, but the grout degrades hydraulically immediately after year 500, after which infiltrate flows downward through the grout. For this configuration, the chemical transition of the $\mathrm{CZ}$ is still based on the overlying grout.

For Configuration $\mathrm{C}$, a fast flow path through the grout exists, but the grout fails hydraulically as it does in the base case. Since the overlying grout remains intact longer, the infiltrate is able to bypass the tank grout (via the fast-flow path) and flow through the $\mathrm{CZ}$. For these configurations the $\mathrm{CZ}$ is based on its own pore water count. The fast-flow configuration is the same for Configuration B. The Configuration $\mathrm{C}$ replacement material zones are shown in Table 8.

Table 8 - Zones for Replacement (Configuration C)

\begin{tabular}{|l|l|}
\hline Material Zone & Zone For Transition \\
\hline BASE_NON_PORE & BASEMAT \\
\hline ROOF_NON_PORE & ROOF \\
\hline WALL_NON_PORE & WALL \\
\hline CENTER_RISER & ROOF \\
\hline DOME_RING & ROOF \\
\hline FF_BASEMAT & BASEMAT \\
\hline
\end{tabular}

For Configuration D, the fast flow path exists through the basemat, as well as the roof and grout. The $\mathrm{CZ}$ is the same as in Configuration B. For Configuration E, the fast flow path is the same as it is for $\mathrm{D}$. The $\mathrm{CZ}$ is based on its own pore water count, just as in Configuration $\mathrm{C}$. The replacement zones for these two configurations are shown in Table 9 and Table 10.

Table 9 - Zones for Replacement (Configuration D)

\begin{tabular}{|l|l|}
\hline Material Zone & Zone For Transition \\
\hline BASE_NON_PORE & BASEMAT \\
\hline ROOF_NON_PORE & ROOF \\
\hline WALL_NON_PORE & WALL \\
\hline CENTER_RISER & ROOF \\
\hline DOME_RING & ROOF \\
\hline CONTAM_ZONE & TANK_GROUT \\
\hline
\end{tabular}


Table 10 - Zones for Replacement (Configuration E)

\begin{tabular}{|l|l|}
\hline Material Zone & Zone For Transition \\
\hline BASE_NON_PORE & BASEMAT \\
\hline ROOF_NON_PORE & ROOF \\
\hline WALL_NON_PORE & WALL \\
\hline CENTER_RISER & ROOF \\
\hline DOME_RING & ROOF \\
\hline
\end{tabular}

The above transitions concern the cementitious materials. For the soil, a leachate and a nonleachate condition exist. The leachate condition only applies to the tanks that are above grade Types III, IIIA, and IV. The leachate condition exists when pore water flows through the cementitious material and into the soil. The leachate $\mathrm{Kd}$ values were applied at the outset for the native and backfill soil for the applicable type tanks. The transition from the leachate Kd values back to the standard values - for example SandyLeachate to Sandy - is associated with the $\mathrm{pH}$ transition for the tank grout. After the $\mathrm{pH}$ transition of the grout, the leachate would have been removed from the grout and would no longer be in the underlying soil. The initial leachate conditions are applied to the entire soil regions. For any regions in the soil that have contaminant from the tank, the leachate condition would exist. Regions in the soil that are not in the leachate condition, would not have contaminants from the tank, so using the leachate $\mathrm{Kd}$ instead of the non-leachate $\mathrm{Kd}$ would have no impact.

The cross-flow factor, as defined by Equation (6), is applied to the zones that are beneath the water table. The Type I tanks are fully submerged, so the cross-flow factor is applied to every zone. The Type II tanks are only partially submerged. Because the basemat is fully submerged, the cross-flow factor is applied to this zone. The roof is completely above the water table, so the cross-flow factor is not applied to this zone. Only a small portion of the wall and grout of the Type II tanks is submerged - less than 5\% of the total height. Because the cross-flow could only affect a small portion of the total zone, the impact from the cross-flow would be small. Applying the cross-flow to the entire region would lead to an unrealistically early transition time. Therefore the cross-flow factor is neglected for the tank grout and wall. The contamination zone, which is fully beneath the water table, gets its pore volume count from the overlying tank grout for Cases A, B, and D. For Cases $\mathrm{C}$ and $\mathrm{E}$, the scenario exists that the grout stays intact longer and water from above the tank comes down the fast-flow path and contacts the contamination zone. Because the flow would be down the fast-flow path, any cross-flow impact would be negligible for the contamination zone in these cases. Therefore, the cross-flow factor is not applied to the contamination zone for Type II tanks. Type III, IIIA and IV tanks are above the water table.

\subsection{Model Results}

\subsection{Results}

The concentration values from PORFLOW are used as input for a GoldSim dose calculator. The dose results are presented in the PA and are not duplicated here. Aquifer concentration results were computed at the seepline and along the $100-\mathrm{m}$ boundary. The $100-\mathrm{m}$ boundary was divided 
into different regions for the dose results. Concentration results for anywhere along the 100-m boundary are presented in Appendix B, grouped by the parent species.

\subsection{PORFLOW Versions and QA}

Version 6.30.2 of PORFLOW was used to accomplish HTF PA simulations. Version 6.30.2 is the latest site version of PORFLOW and contains the "STRAtified" aquifer dispersion model and the greater limit on the number of "STATistics" files, which were identified as necessary for the prior work. QA testing for these versions is summarized by Whiteside (2010).

\subsection{Directory Structure and Key Electronic Files}

All of the results from the PORFLOW modeling are stored on the SRNL High Performance Computing Servers. At the top level directory, folders exist for each vadose model that was evaluated in PORFLOW. In general, these are associated with the type tank. When different models were needed for the same type tank, a separate directory was created. For example, the Type IIIA tanks on the West hill had a different depth to water table from the other Type III tanks. As a result, two separate grids were created and the models were run for Type IIIA and IIIAWest separately. The Type IIIA results are in the directory VadoseTypeIIIA and the IIIA West results are in VadoseTypeIIIAWest. The relevant top level vadose directories are:

- VadoseTypeI

- VadoseTypeI_noliner

- VadoseTypeII

- VadoseTypeII_noliner

- VadoseTypeIII

- VadoseTypeIIIA

- VadoseTypeIIIAWest

- VadoseTypeIV

- VadoseAncillaryEquip1

- VadoseAncillaryEquip2

- VadoseAncillaryEquip3

- VadoseAncillaryEquip4

- VadoseAncillaryEquip5

- VadoseAncillaryEquip6

- VadoseAncillaryEquip7

- VadoseAncillaryPipe1

- VadoseAncillaryPipe2

- VadoseAncillaryPipe3

- VadoseAncillaryPipe4

Within each vadose directory are Flow and Transport directories. The flow results are within the Flow directory, organized by case and time period. The transport results are within the Transport directory, organized by case, tank, and nuclide. 
The aquifer results follow a similar structure as the vadose results. Two top level aquifer folders exist for the seepline - AquiferGSA - and the 100m boundary - AquiferHTF. Within each aquifer folder is a Transport folder with results organized by case, source, and nuclide. Summaries of key results for each case and source are organized by output location, e.g. sector or aquifer.

The top-level directory is located on $\backslash$ ggodzilla-01 $\backslash \mathrm{hpc}$ project $\mid$ projwork27\htank $\backslash$ new_htf_rev1. Additional files are located on $\backslash$ godzilla- $01 \backslash \mathrm{hpc}$ project $\backslash$ projwork60 $\backslash$ htank $\backslash$. At a later date, the files will be moved to an archive location to preserve file integrity.

\subsection{Conclusions}

The PORFLOW models for the H-Tank Farm PA, Rev. 1 were updated with grout, solubility, and inventory changes. The aquifer model was refined. In addition, a set of flow sensitivity runs were performed to allow flow to be varied in the related probabilistic GoldSim models. The final PORFLOW concentration values are used as input into a GoldSim dose calculator. The final doses for the various cases are presented in the PA (SRR 2012) and are not duplicated here. 
SRNL-STI-2012-00465

\subsection{References}

Aleman, S. and G. Flach. 2010. Acceptance Testing for PORFLOW version 6.30.1, SRNLL6200-2010-00016. September 1.

Almond, P. M. and Kaplan, D. I. 2011. Distribution Coefficients (Kd) Generated from a Core Sample Collected from the Saltstone Disposal Facility. Savannah River Site, Aiken, SC. SRNLSTI-2010-00667, Rev. 0.

Almond, P. M., et al. 2012. Variability of Kd Values in Cementitious Materials and Sediments. Savannah River Site, Aiken, SC. SRNL-STI-2011-00672, Rev. 0.

Burnett, R. D. and E. O. Frind. 1987. Simulation of contaminant transport in three dimensions; 2. Dimensionality effects. Water Resources Research v32 n 4 695-705.

Dean, B. 2012. H-Tank Farm Waste Tank Closure Inventory for Use in Performance Assessment Modeling. Savannah River Site, Aiken, SC. SRR-CWDA-2010-00023, Rev. 3.

Denham, M. E. and Millings, M. 2012. Evolution of Chemical Conditions and Estimated Solubility Controls on Radionuclides in the Residual Waste Layer During Post-Closure Aging of High-Level Waste Tank. Savannah River Site, Aiken, SC. SRNL-STI-2012-00404, Rev. 0.

Denham, M. E. 2010. Conceptual Model of Waste Release from the Contaminated Zone of Closed Radioactive Waste Tanks. WSRC-STI-2007-00544, Rev. 2.

Dixon, K. and M. Phifer. 2007. Hydraulic And Physical Properties Of Tank Grouts And Base Mat Surrogate Concrete For FTF Closure. WSRC-STI-2007-00369, Rev. 0.

Flach, G. P. 2004. Groundwater Flow Model Of The General Separations Area Using Porflow (U). WSRC-TR-2004-00106.

Flach, G. P. 2009. Dispersion Modeling in the 2008 E-Area Performance Assessment (PA). SRNL-L6200-2009-00049.

Flach, G. P., J. M. Jordan and T. Whiteside. 2009. Numerical flow and transport simulations supporting the Saltstone Disposal Facility Performance Assessment. SRNL-STI-2009-00115, Rev. 1.

Flach, G.P. 2012. Effective Porosity Implies Effective Bulk Density in Sorbing Solute Transport. Ground Water. doi: 10.1111/j.1745-6584.2012.00934.x.

Flach, G.P. 2012. Software Quality Assurance Plan for Aquifer Model Refinement Tool (MESH3D). Q-SQP-G-00003, Rev. 1.

Gelhar, L. W., C. Welty, and K. R. Rehfeldt. 1992. A critical review of data on field-scale dispersion in aquifers. Water Resour. Res. 28(7), 1955-1974. 
Hamm, L. L. and S. E. Aleman. 2000. FACT (Version 2.0), Subsurface Flow and Contaminant Transport, Documentation and User's Guide (U). WSRC-TR-99-00282, Rev. 0.

Jordan, J.M., G.P. Flach and D. Schep. 2010. PORFLOW Modeling Supporting the H-Tank Farm Performance Assessment. SRNL-L6200-2010-00026, Rev. 1.

Kaplan, D. I. 2010. Geochemical Data Package for Performance Assessment Calculations Related to the Savannah River Site. Savannah River Site, Aiken, SC. SRNL-STI-2009-00473.

Or, D. and M. Tuller. 2000. Flow in unsaturated fractured porous media: Hydraulic conductivity of rough surfaces. Water Resources Research, v. 36, n. 5, 1165-1177.

Phifer, M. A., M. R. Millings and G. P. Flach. 2006. Hydraulic Property Data Package For The E-Area And Z-Area Soils, Cementitious Materials, And Waste Zones. WSRC-STI-2006-00198, $344 \mathrm{p}$.

PORTAGE Inc. 2008. H-area Tank Farm model development for tanks in the water table, Porflow version 6.20.0. PORTAGE-08-022, Rev. 0.

Powell, B. A., Lilly, M. A., Miller, T. J., Kaplan, D. I. 2010. Iodine, Neptunium, Radium, and Strontium Sorption to Savannah River Site Sediment. Savannah River Site, Aiken, SC. SRNLSTI-2010-00527, Rev. 0.

Scheidegger, A. E. 1961. General Theory of Dispersion in Porous Media. Journal Of Geophysical Research. vol. 66, no. 10, pp. 3273-3278.

Seaman, J. C., and Kaplan, D. I. 2010. Chloride, Chromate, Silver, Thallium, and Uranium Sorption to SRS Soils, Sediments, and Cementitious Materials. Savannah River Site, Aiken, SC. SRNL-STI-2010-00493, Rev. 0.

SRR. 2011. Performance Assessment for the H-Area Tank Farm at the Savannah River Site, Savannah River Site, Aiken, SC. SRR-CWDA-2010-00128, Rev. 0.

SRR. 2012. Performance Assessment for the H-Area Tank Farm at the Savannah River Site, Savannah River Site, Aiken, SC. SRR-CWDA-2010-00128, Rev. 1 in preparation.

Stefanko, D.B. and C.A. Langton. 2011. Tanks 18 and 19-F Structural Flowable Grout Fill Material Evaluation and Recommendations. SRNL-STI-2011-00551, Rev.0. Savannah River National Laboratory, Aiken, S.C.

Watkins, D. R. 2010. H-Area Tank Farm Grout and Concrete Degradation Modeling Information. SRR-CWDA-2010-00019, Rev. 0.

Whiteside, T. 2010. Software Testing and Verification of PORFLOW Versions 6.30.1 and 6.30.2. SRNL-TR-2010-00213, Rev. 0. 
Zheng, C. and G. D. Bennett. 1995. Applied contaminant transport modeling: Theory and practice. van Nostrand Reinhold, New York. 440 p. 


\section{Appendix A Main PORFLOW input file for numerical simulations}

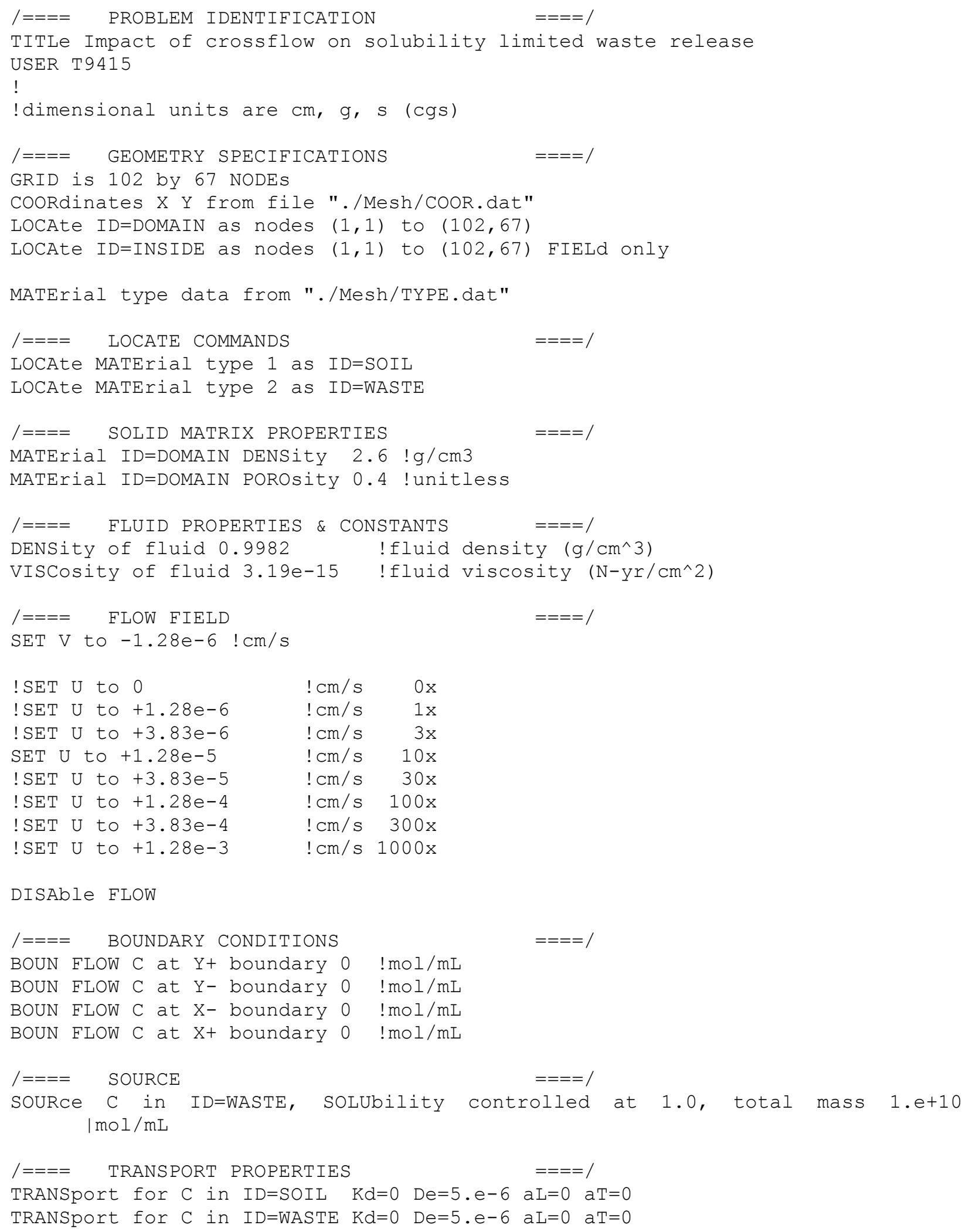




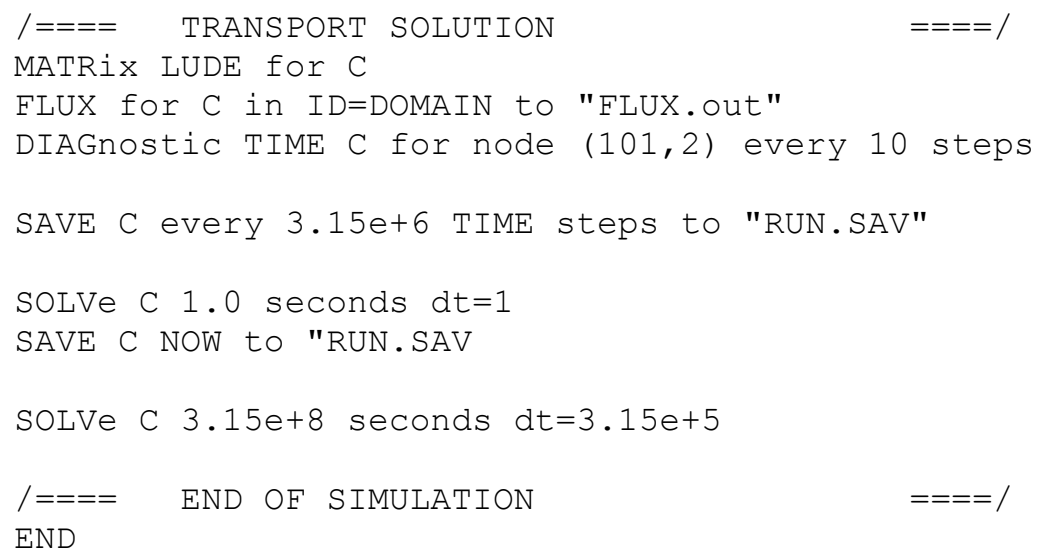




\section{Appendix B 100-meter Concentration Results}

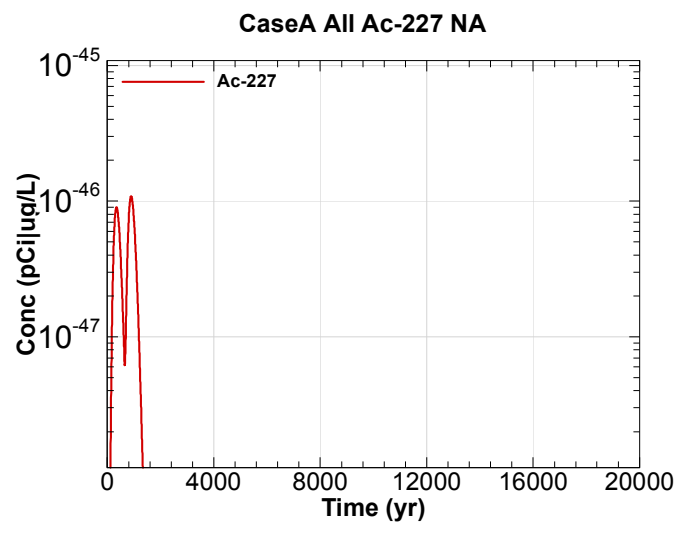

Figure B-1 - 100m Aquifer Concentration for CaseA All Ac-227 NA

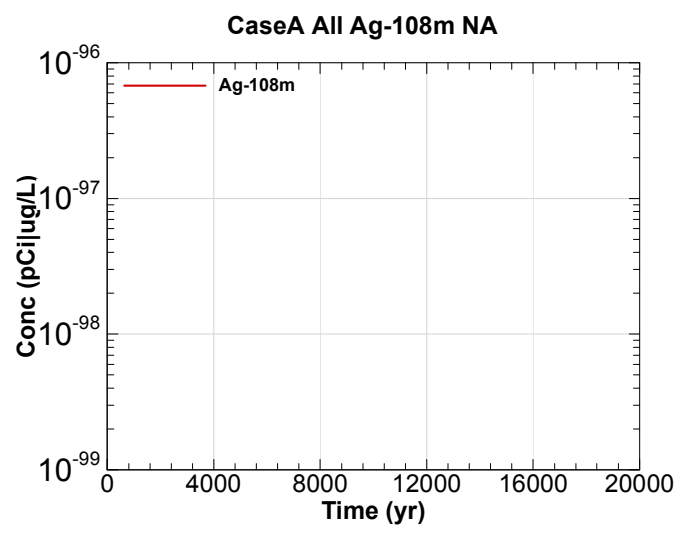

Figure B-3 - 100m Aquifer Concentration for CaseA All Ag-108m NA

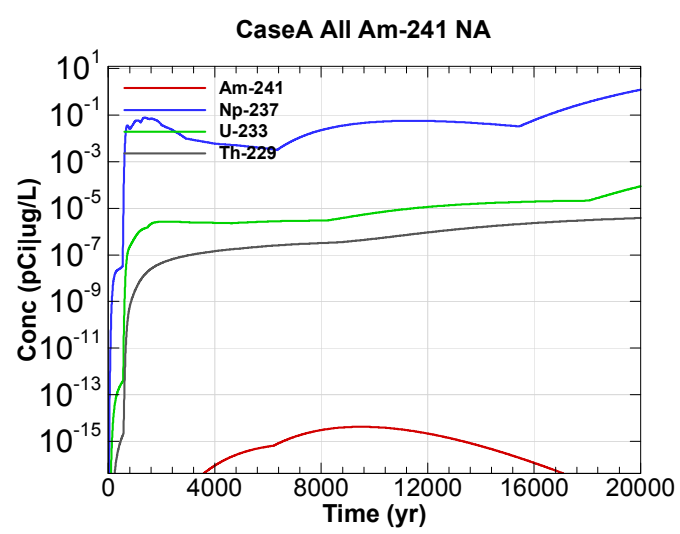

Figure B-5 - 100m Aquifer Concentration for CaseA All Am-241 NA

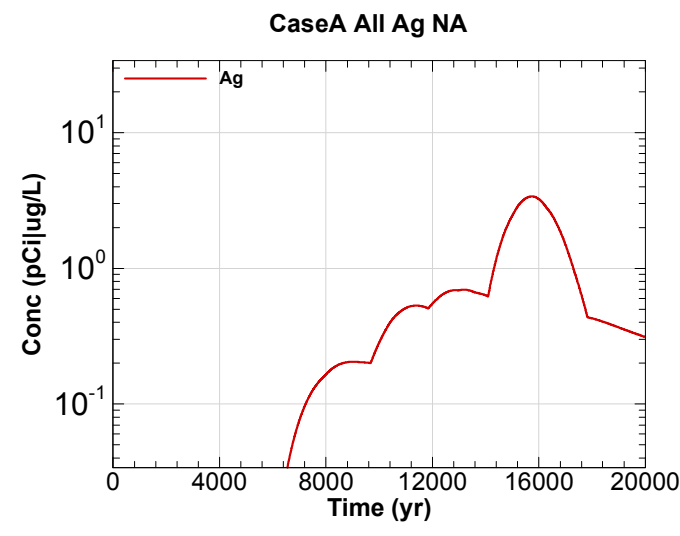

Figure B-2 - 100m Aquifer Concentration for CaseA All Ag NA

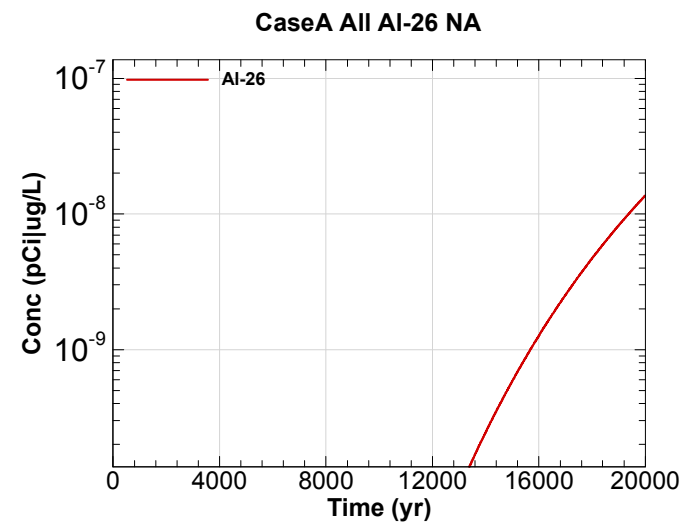

Figure B-4 - 100m Aquifer Concentration for CaseA All Al-26 NA

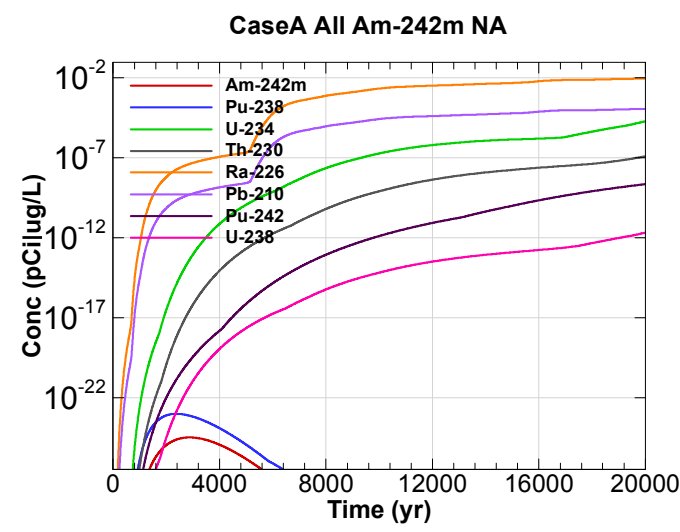

Figure B-6 - 100m Aquifer Concentration for CaseA All Am-242m NA 


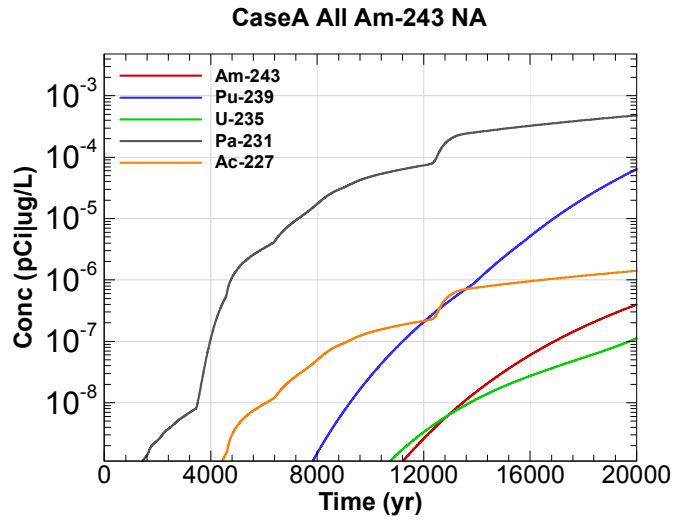

Figure B-7 - 100m Aquifer Concentration for CaseA All Am-243 NA

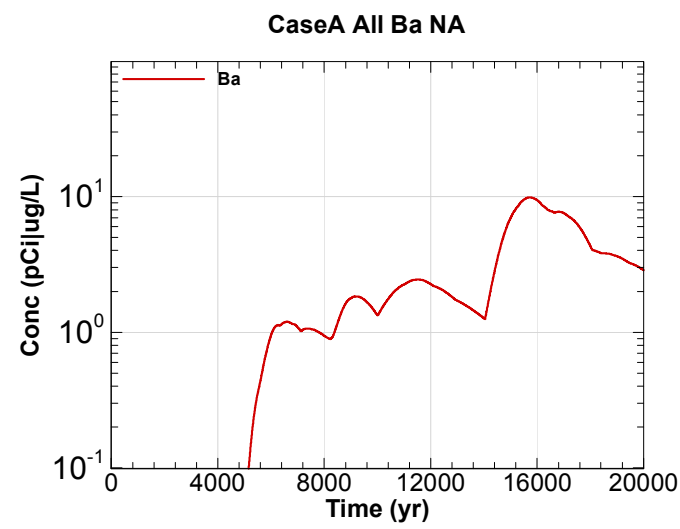

Figure B-9 - 100m Aquifer Concentration for CaseA All Ba NA

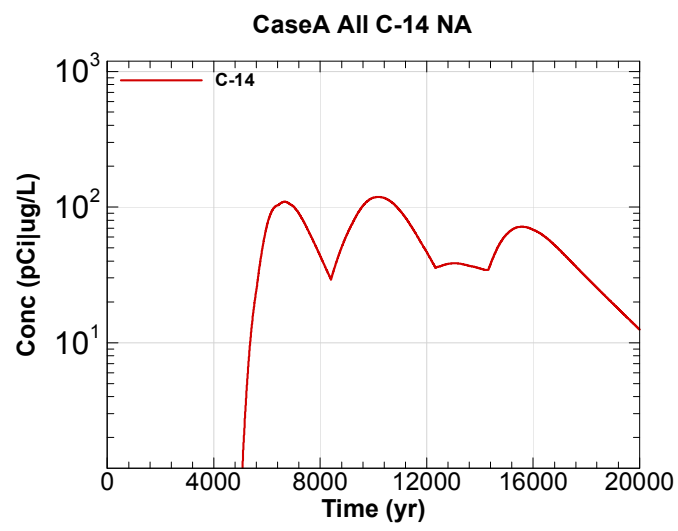

Figure B-11 - 100m Aquifer Concentration for CaseA All C-14 NA

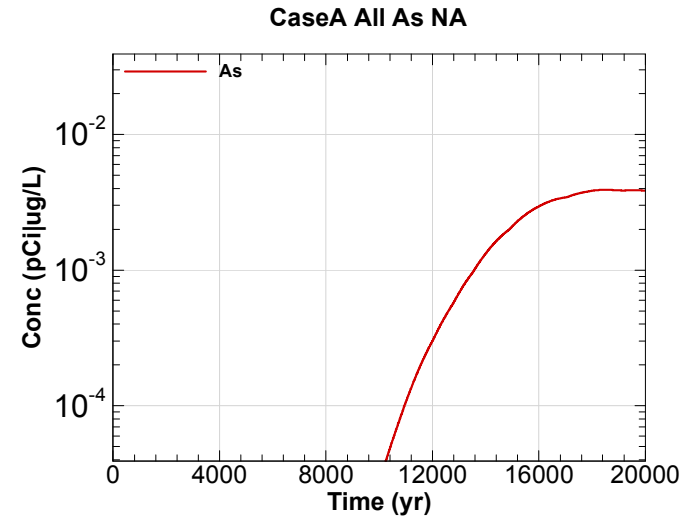

Figure B-8 - 100m Aquifer Concentration for CaseA All As NA

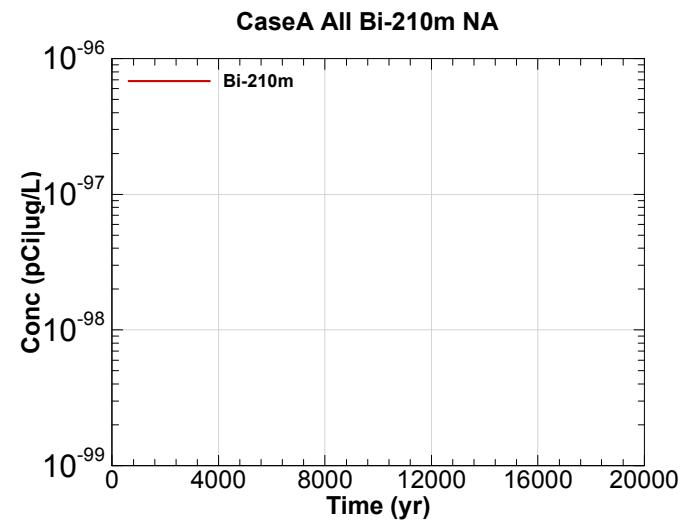

Figure B-10 - 100m Aquifer Concentration for CaseA All Bi-210m NA

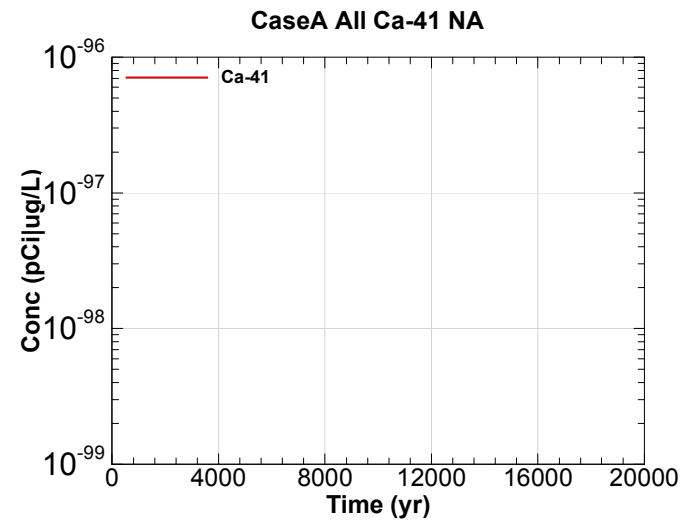

Figure B-12 - 100m Aquifer Concentration for CaseA All Ca-41 NA 


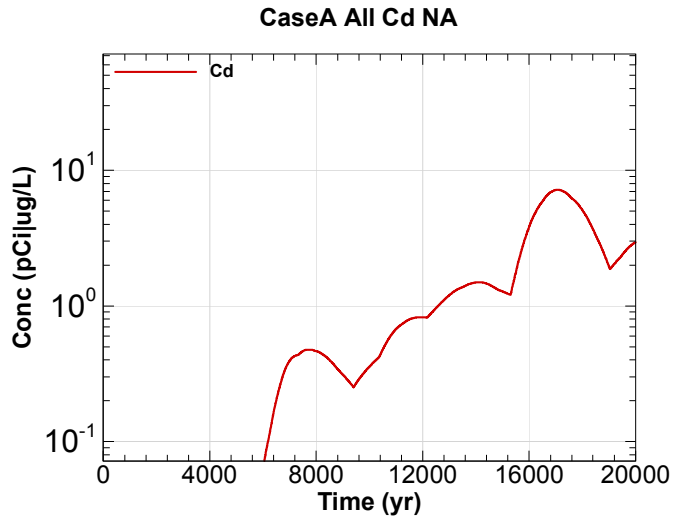

Figure B-13 - 100m Aquifer Concentration for CaseA All Cd NA

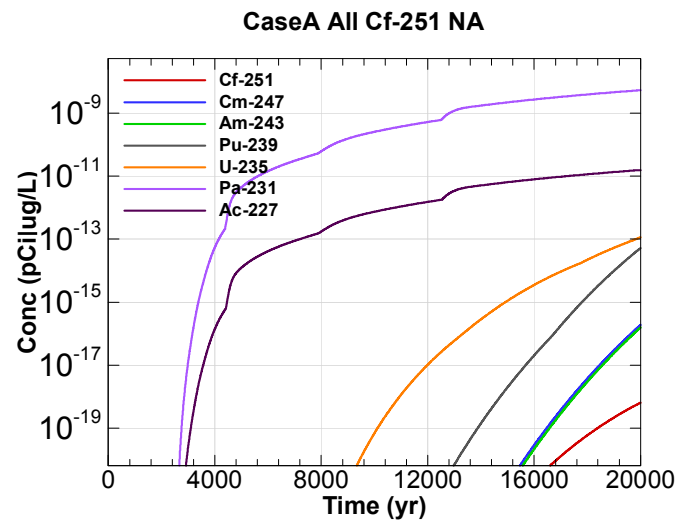

Figure B-15 - 100m Aquifer Concentration for CaseA All Cf-251 NA

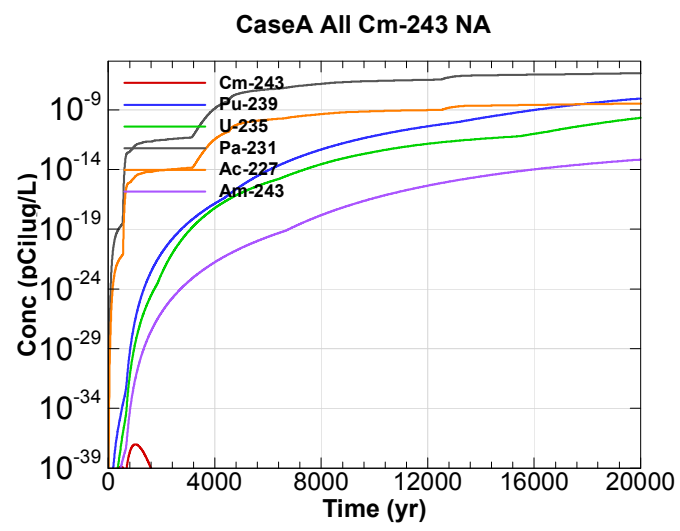

Figure B-17 - 100m Aquifer Concentration for CaseA All Cm-243 NA

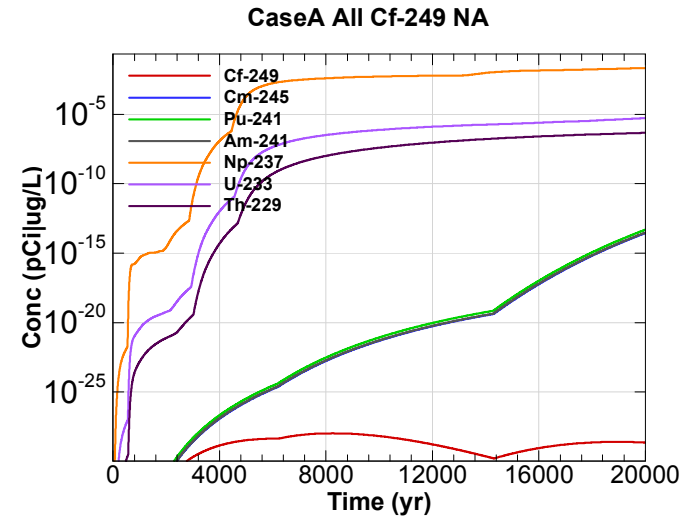

Figure B-14 - 100m Aquifer Concentration for CaseA All Cf-249 NA

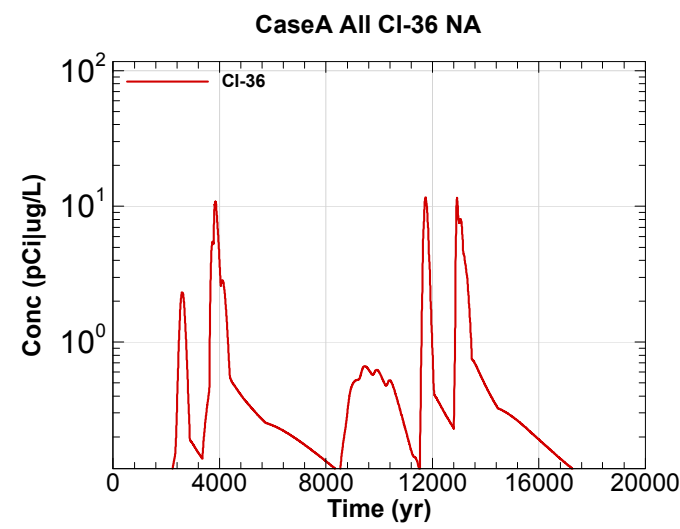

Figure B-16 - 100m Aquifer Concentration for CaseA All Cl-36 NA

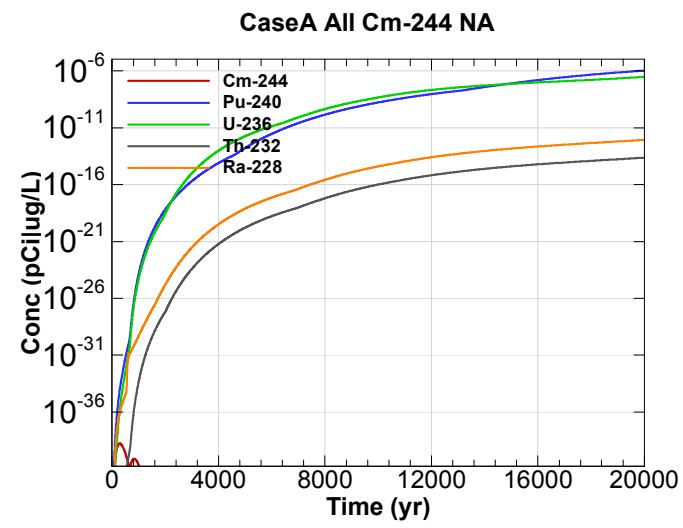

Figure B-18 - 100m Aquifer Concentration for CaseA All Cm-244 NA 


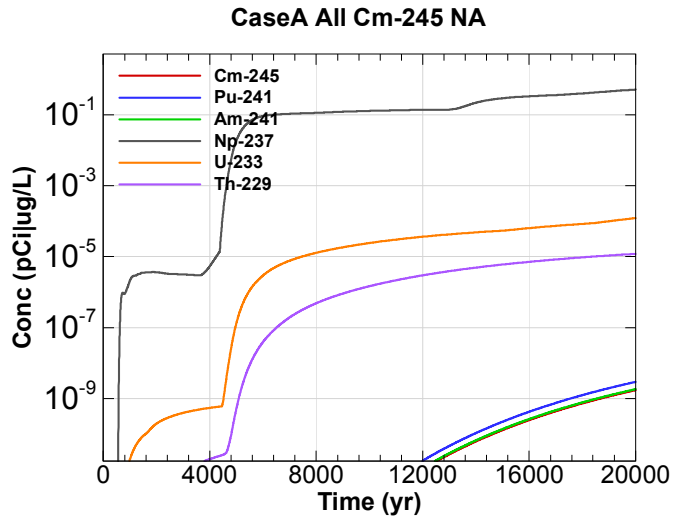

Figure B-19 - 100m Aquifer Concentration for CaseA All Cm-245 NA

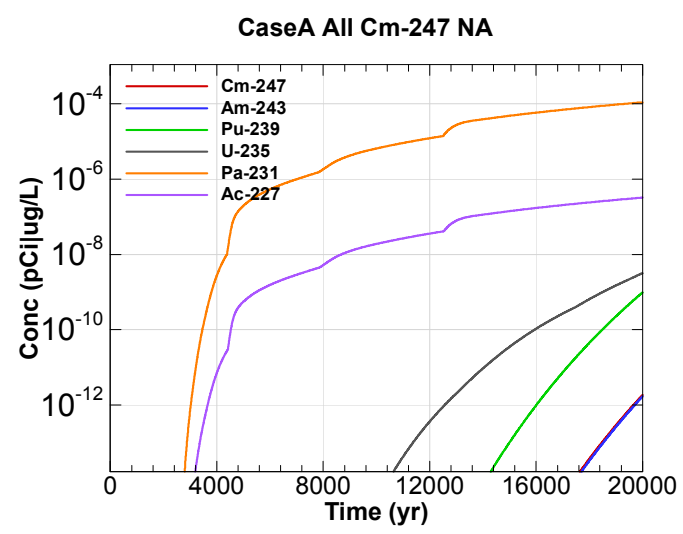

Figure B-21 - 100m Aquifer Concentration for CaseA All Cm-247 NA

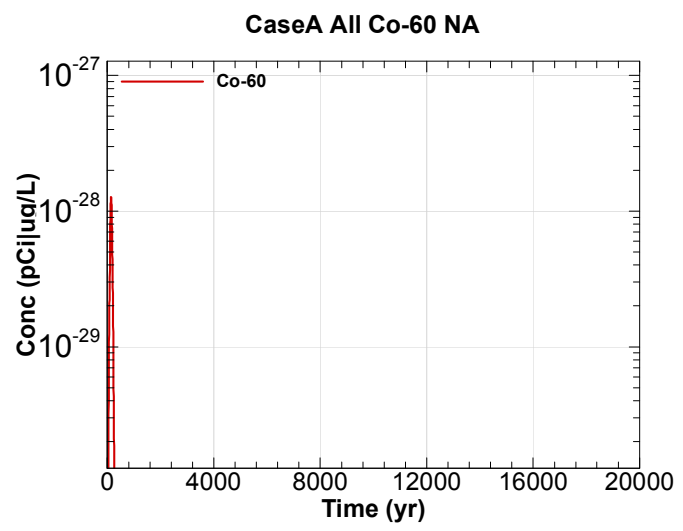

Figure B-23 - 100m Aquifer Concentration for CaseA All Co-60 NA

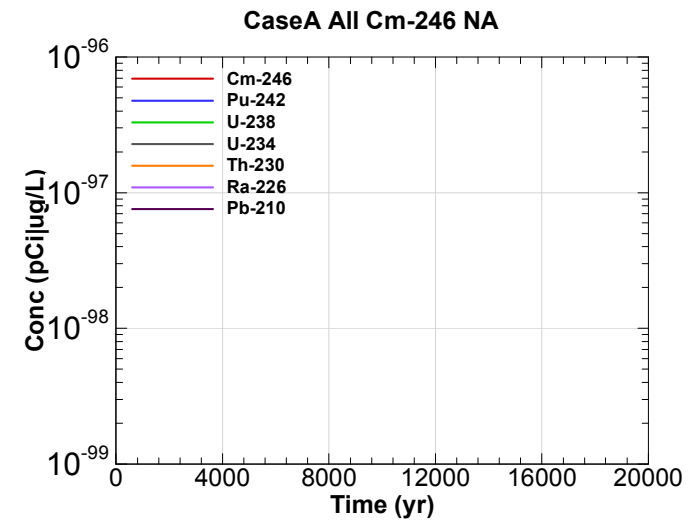

Figure B-20 - 100m Aquifer Concentration for CaseA All Cm-246 NA

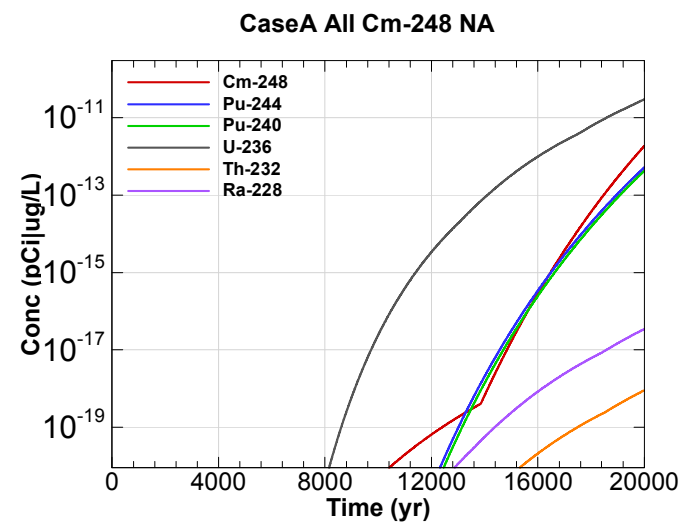

Figure B-22 - 100m Aquifer Concentration for CaseA All Cm-248 NA

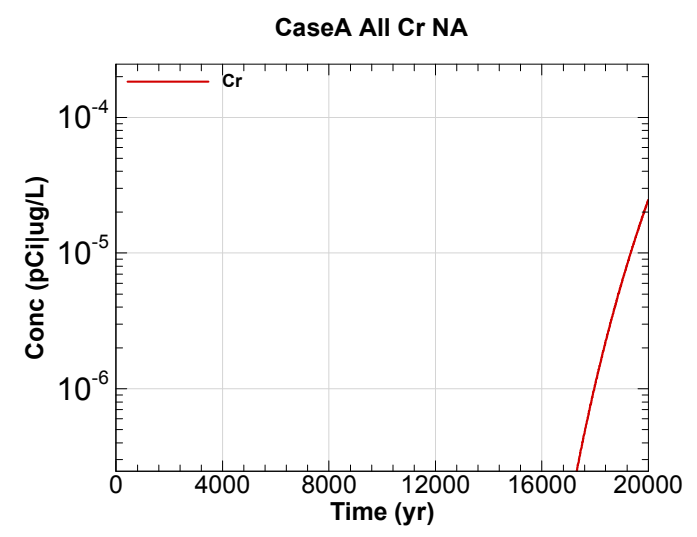

Figure B-24 - 100m Aquifer Concentration for CaseA All Cr NA 


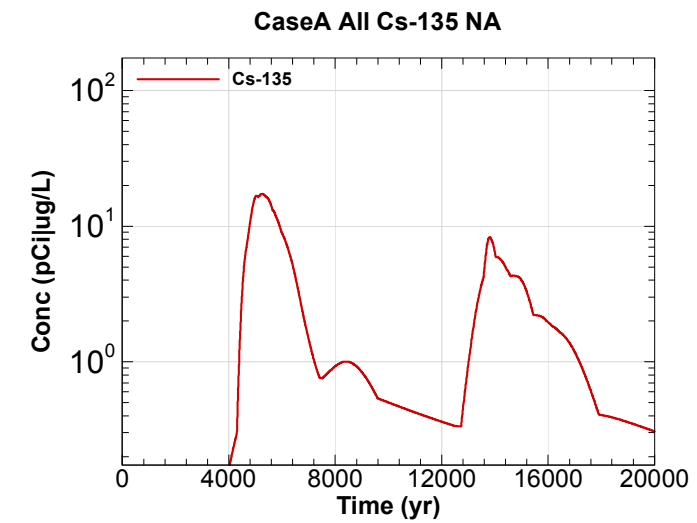

Figure B-25 - 100m Aquifer Concentration for CaseA All Cs-135 NA

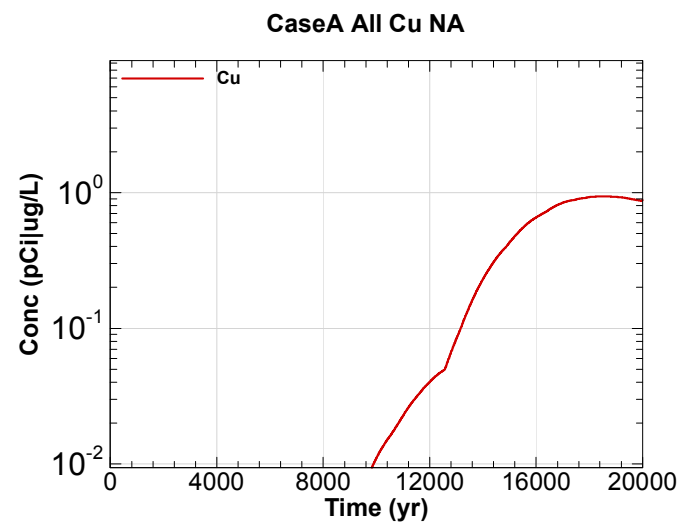

Figure B-27 - 100m Aquifer Concentration for CaseA All Cu NA

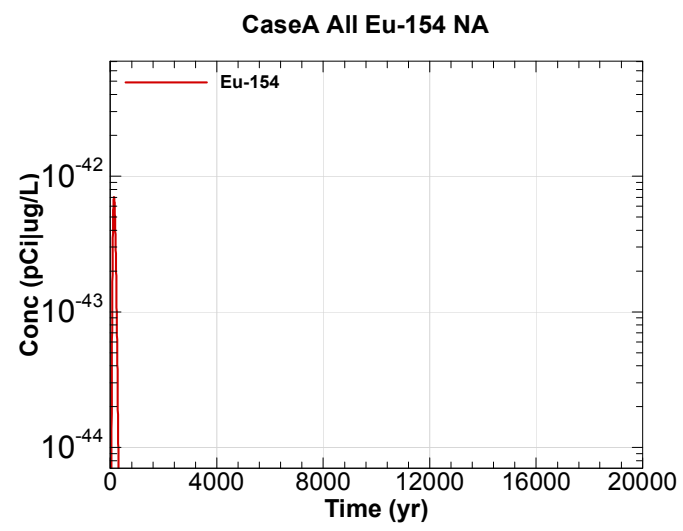

Figure B-29 - 100m Aquifer Concentration for CaseA All Eu-154 NA

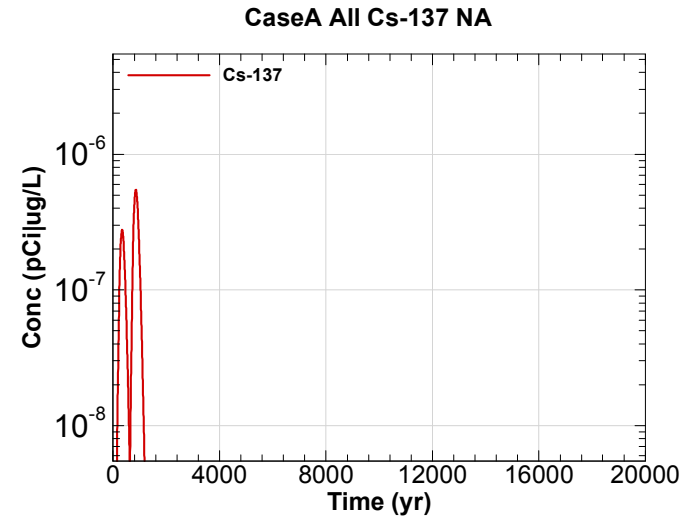

Figure B-26 - 100m Aquifer Concentration for CaseA All Cs-137 NA

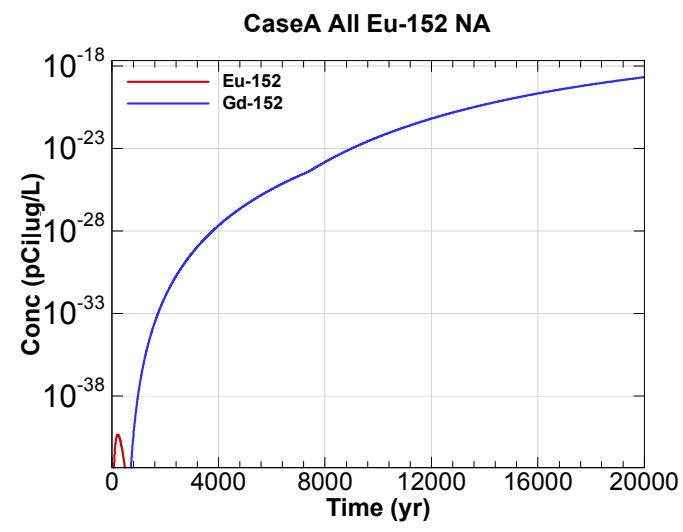

Figure B-28 - 100m Aquifer Concentration for CaseA All Eu-152 NA

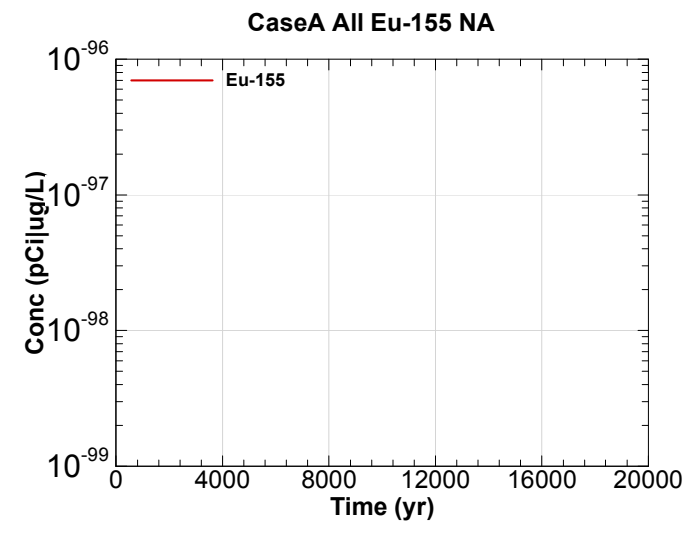

Figure B-30 - 100m Aquifer Concentration for CaseA All Eu-155 NA 


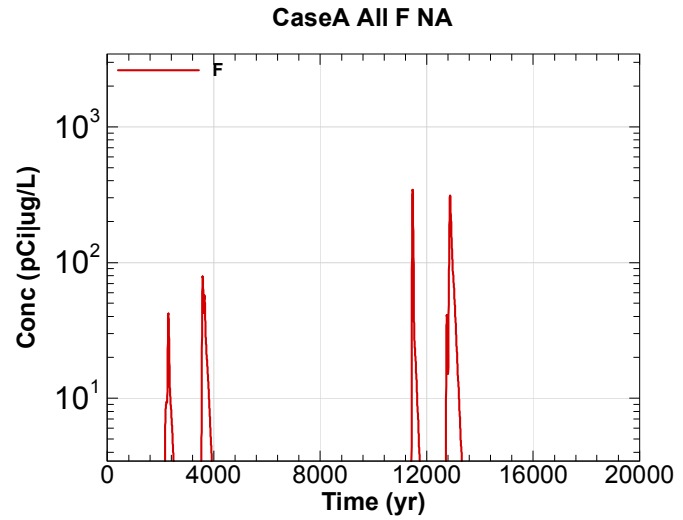

Figure B-31 - 100m Aquifer Concentration for CaseA All F NA

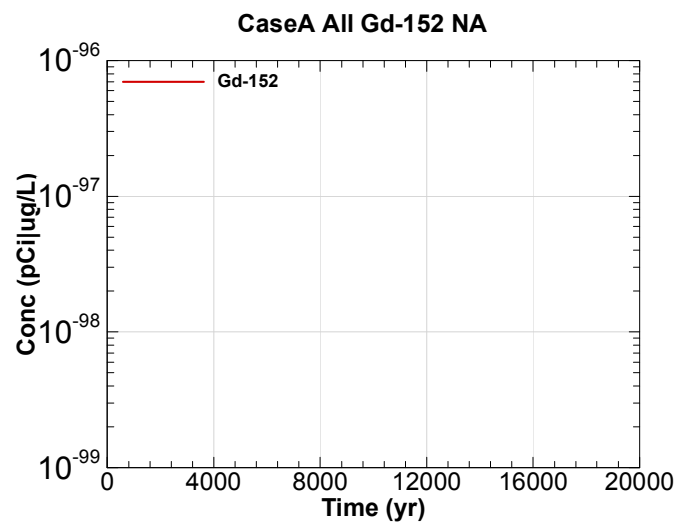

Figure B-33 - 100m Aquifer Concentration for CaseA All Gd-152 NA

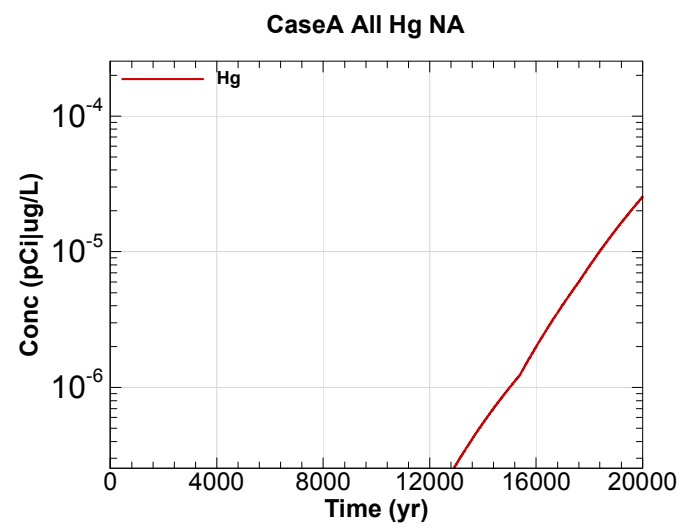

Figure B-35 - 100m Aquifer Concentration for CaseA All Hg NA

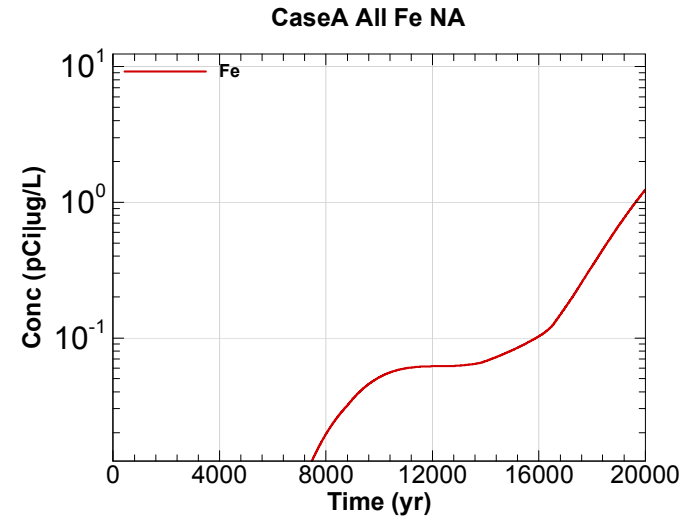

Figure B-32 - 100m Aquifer Concentration for CaseA All Fe NA

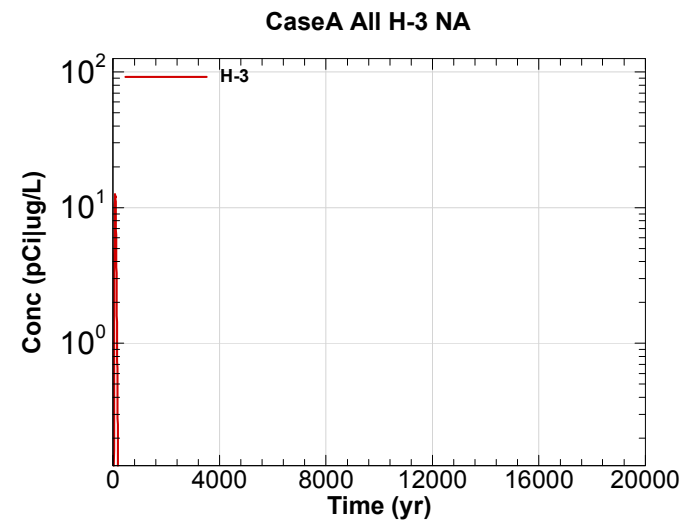

Figure B-34 - 100m Aquifer Concentration for CaseA All H-3 NA

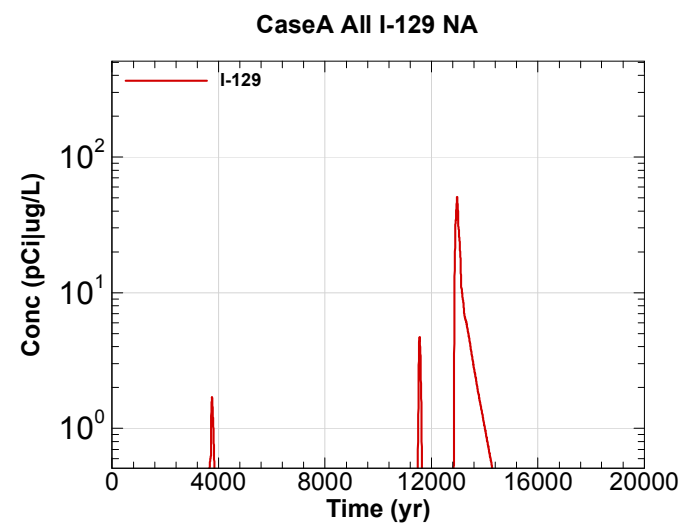

Figure B-36 - 100m Aquifer Concentration for CaseA All I-129 NA 


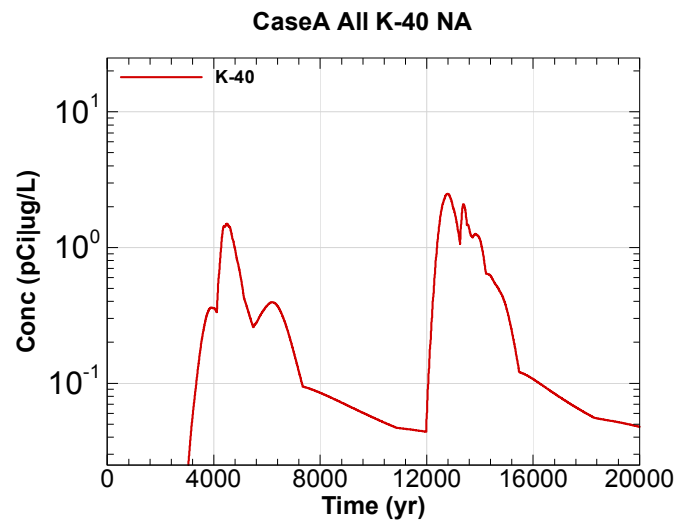

Figure B-37 - 100m Aquifer Concentration for CaseA All K-40 NA

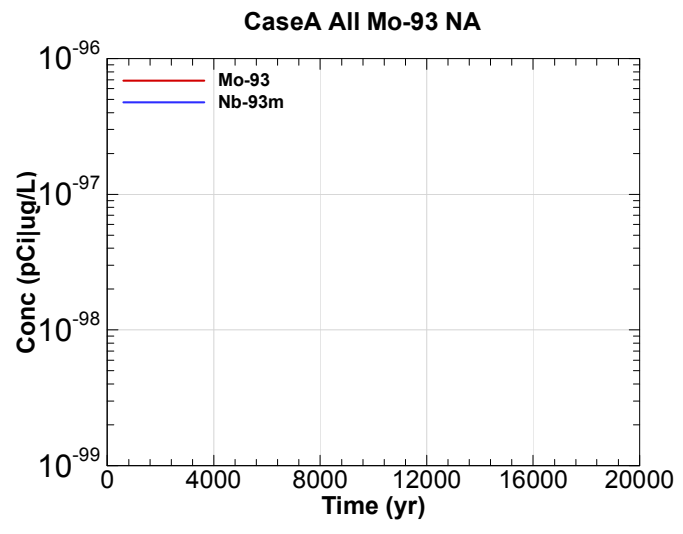

Figure B-39 - 100m Aquifer Concentration for CaseA All Mo-93 NA

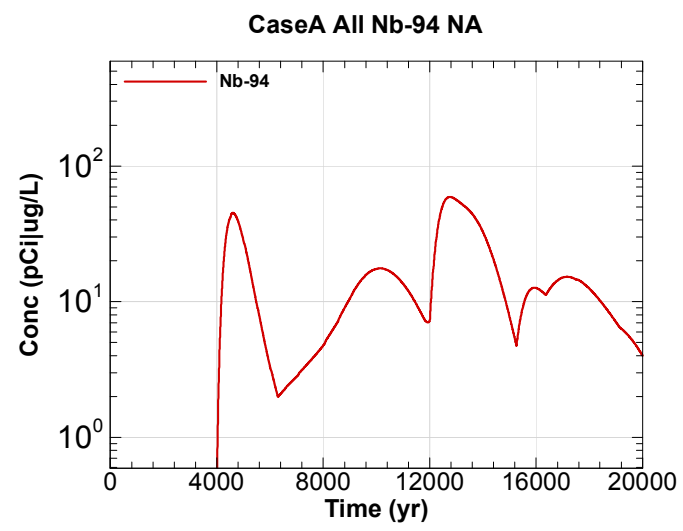

Figure B-41 - 100m Aquifer Concentration for CaseA All Nb-94 NA

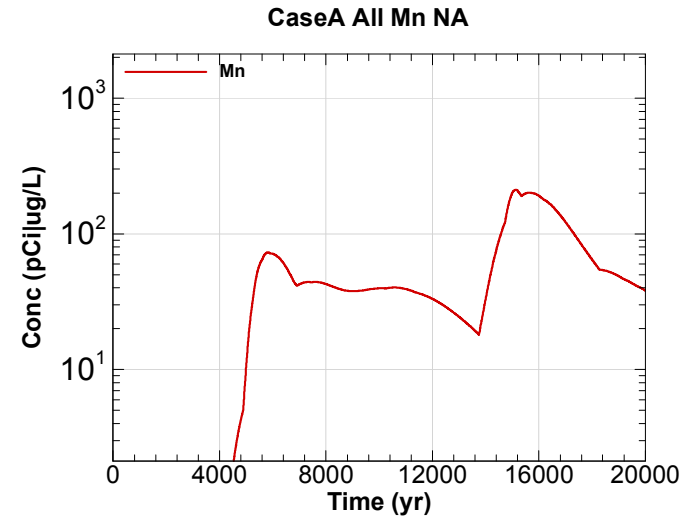

Figure B-38 - 100m Aquifer Concentration for CaseA All Mn NA

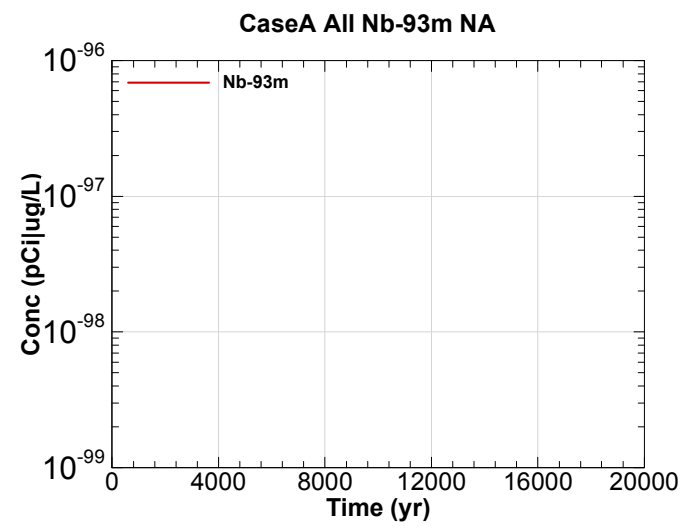

Figure B-40 - 100m Aquifer Concentration for CaseA All Nb-93m NA

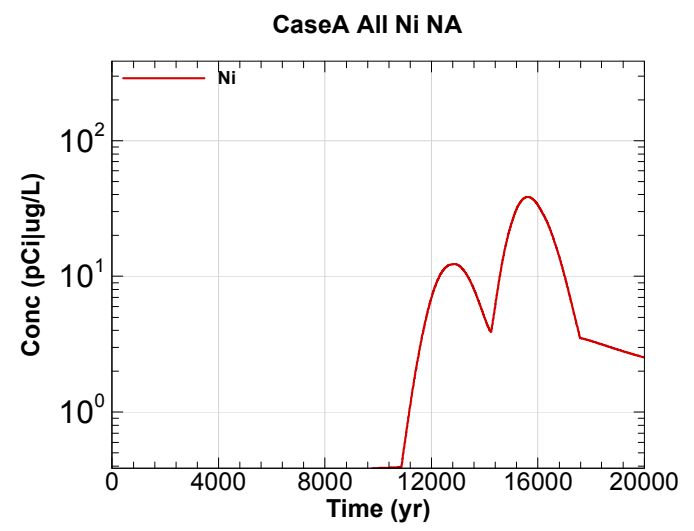

Figure B-42 - 100m Aquifer Concentration for CaseA All Ni NA 


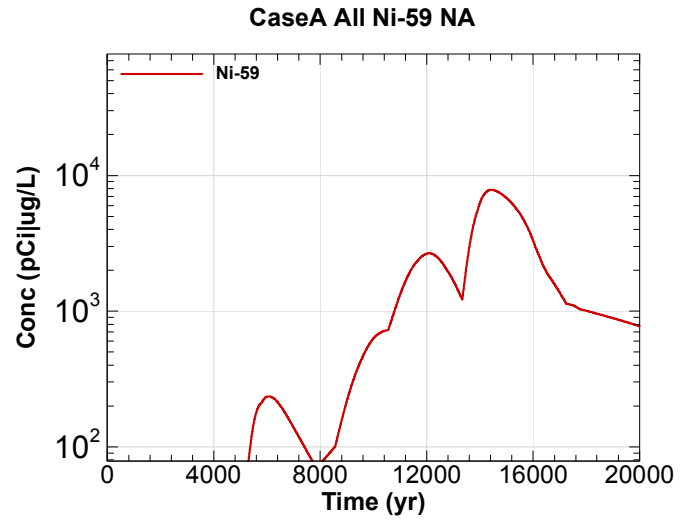

Figure B-43 - 100m Aquifer Concentration for CaseA All Ni-59 NA

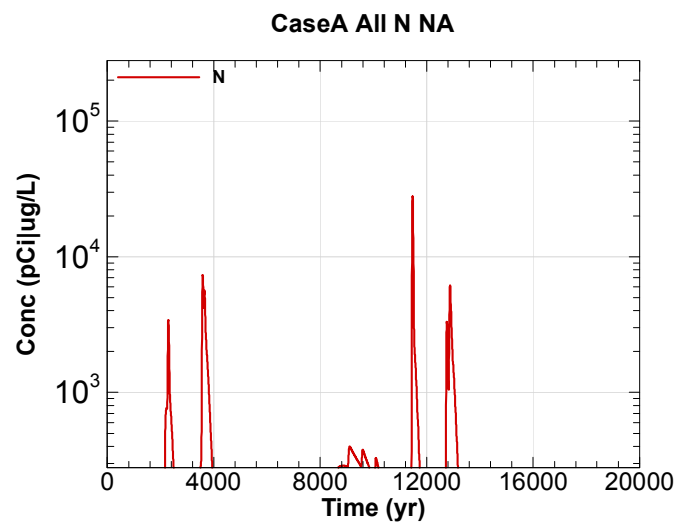

Figure B-45 - 100m Aquifer Concentration for CaseA All N NA

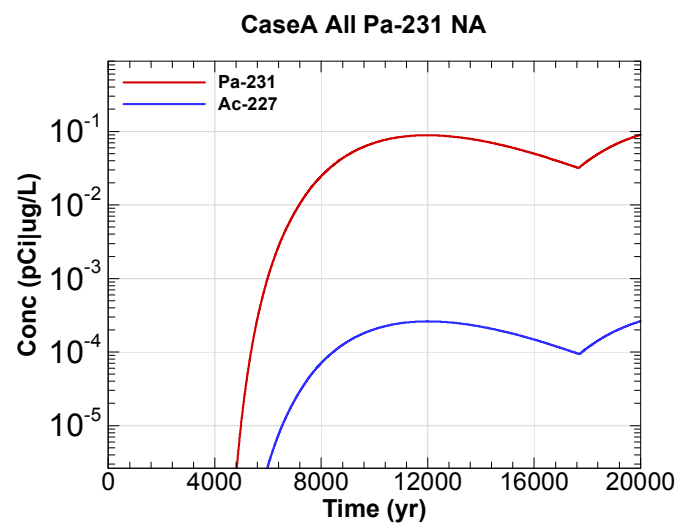

Figure B-47 - 100m Aquifer Concentration for CaseA All Pa-231 NA

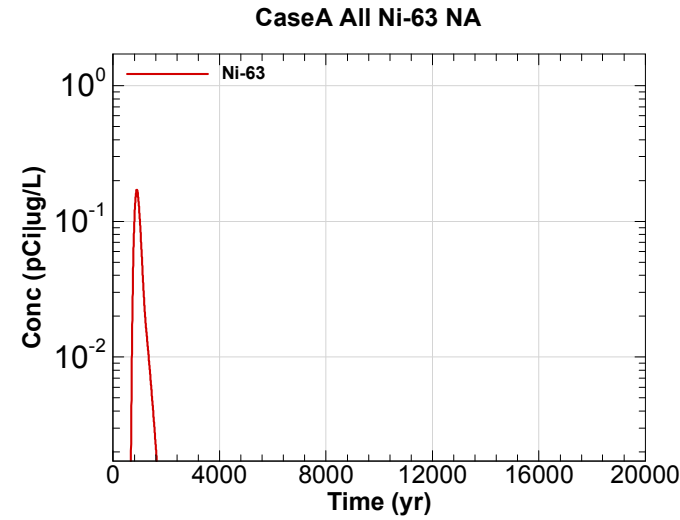

Figure B-44 - 100m Aquifer Concentration for CaseA All Ni-63 NA

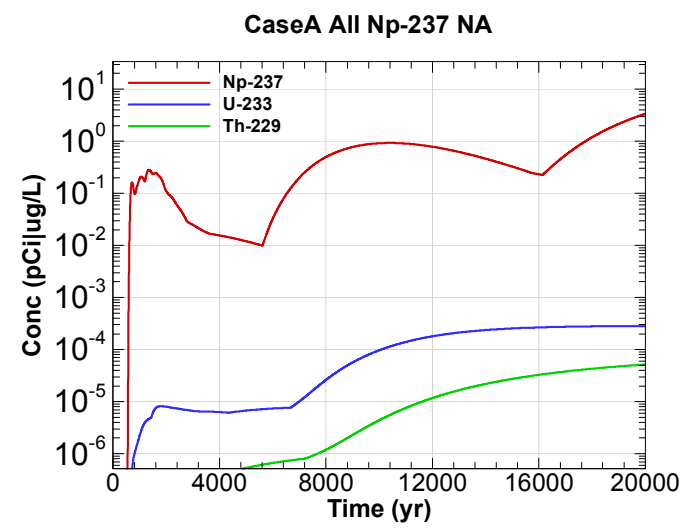

Figure B-46 - 100m Aquifer Concentration for CaseA All Np-237 NA

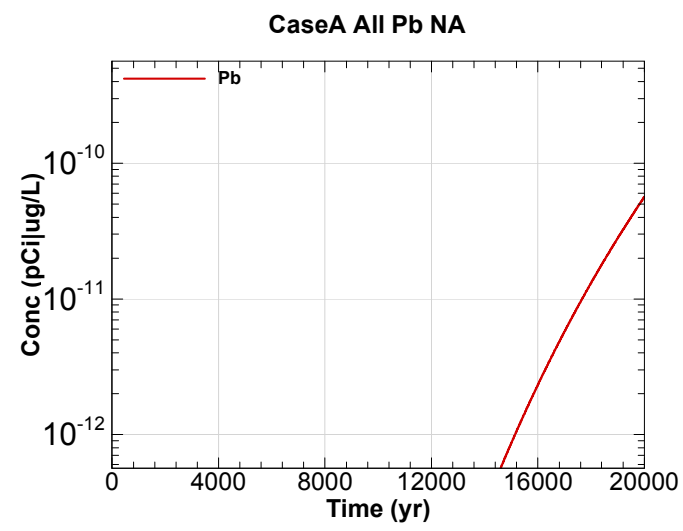

Figure B-48 - 100m Aquifer Concentration for CaseA All Pb NA 


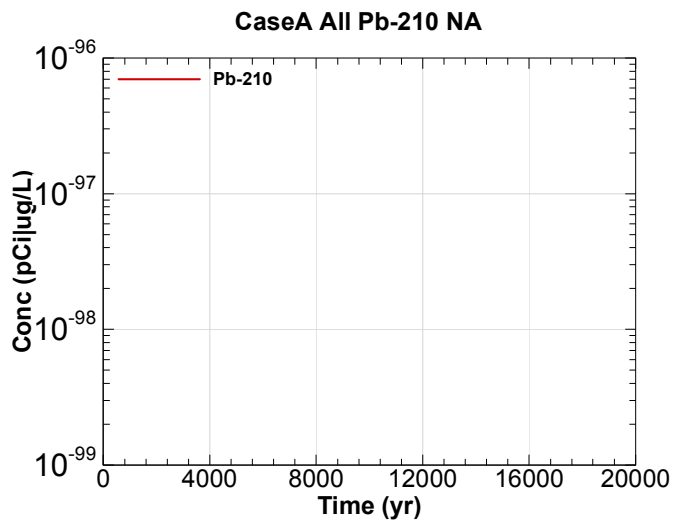

Figure B-49 - 100m Aquifer Concentration for CaseA All Pb-210 NA

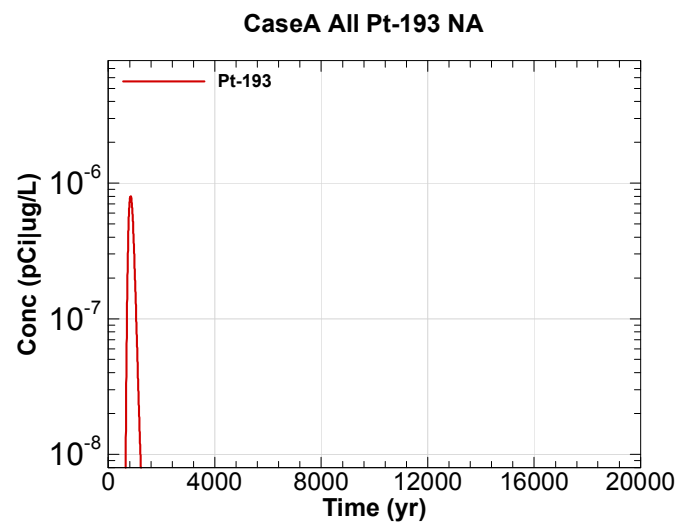

Figure B-51 - 100m Aquifer Concentration for CaseA All Pt-193 NA

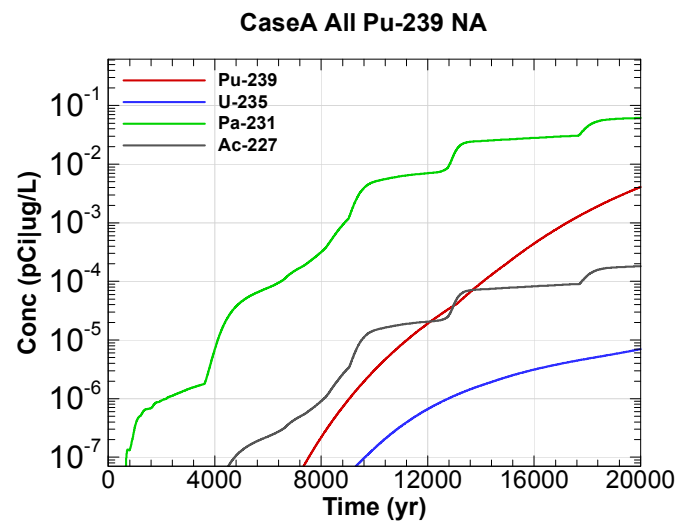

Figure B-53 - 100m Aquifer Concentration for CaseA All Pu-239 NA

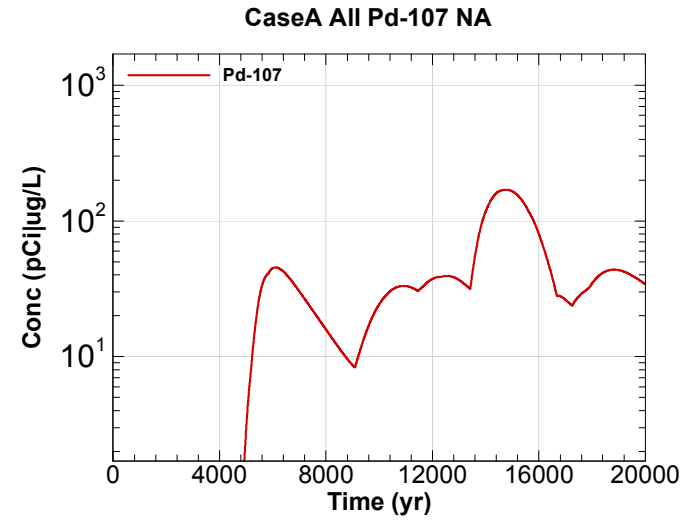

Figure B-50 - 100m Aquifer Concentration for CaseA All Pd-107 NA

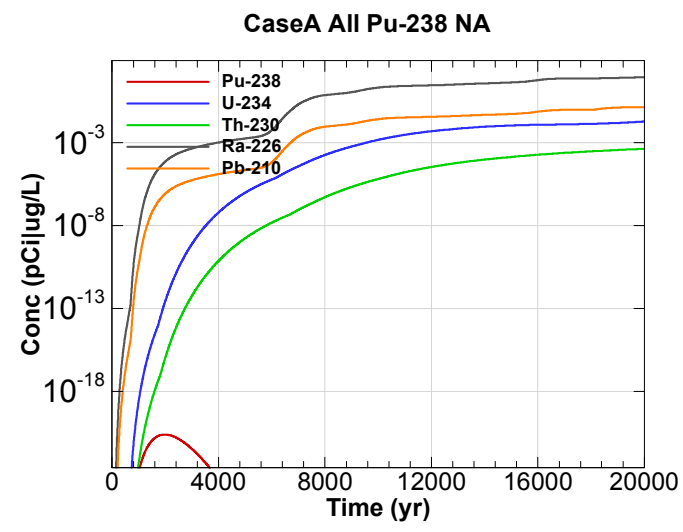

Figure B-52 - 100m Aquifer Concentration for CaseA All Pu-238 NA

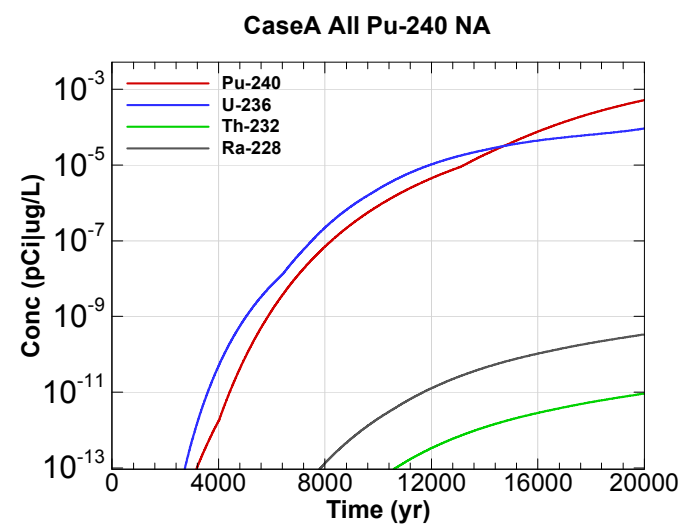

Figure B-54 - 100m Aquifer Concentration for CaseA All Pu-240 NA 


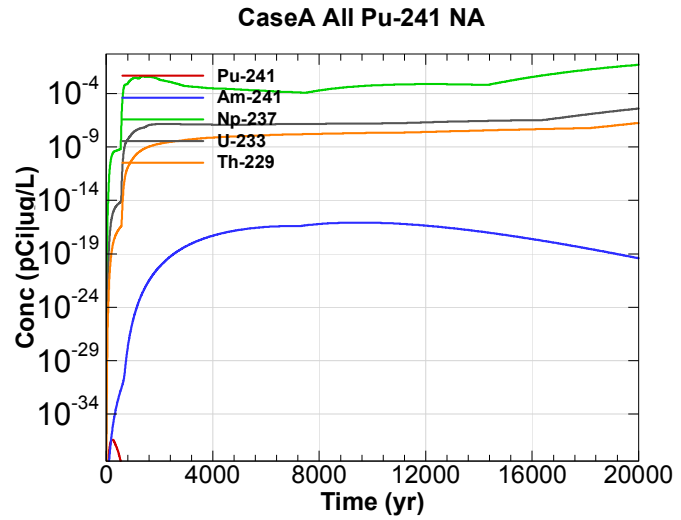

Figure B-55 - 100m Aquifer Concentration for CaseA All Pu-241 NA

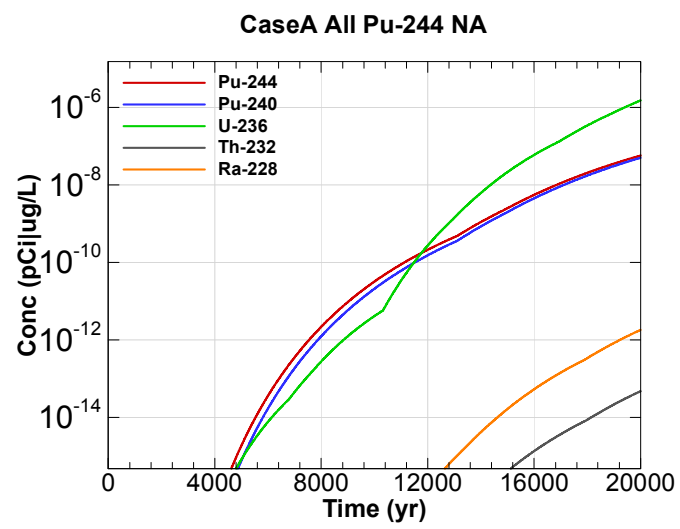

Figure B-57 - 100m Aquifer Concentration for CaseA All Pu-244 NA

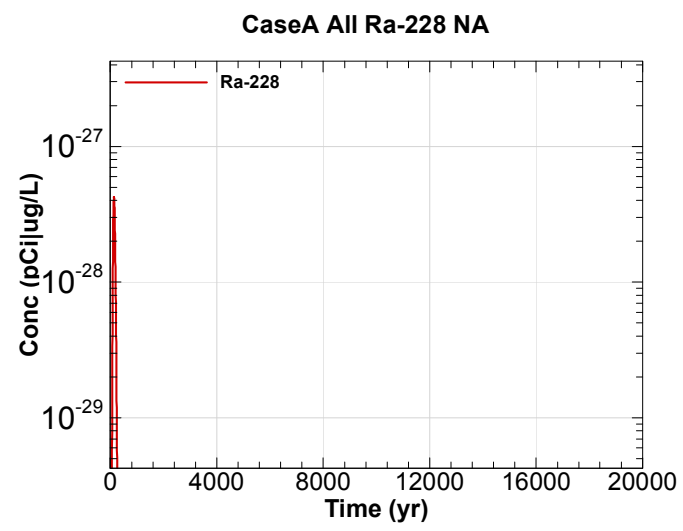

Figure B-59 - 100m Aquifer Concentration for CaseA All Ra-228 NA

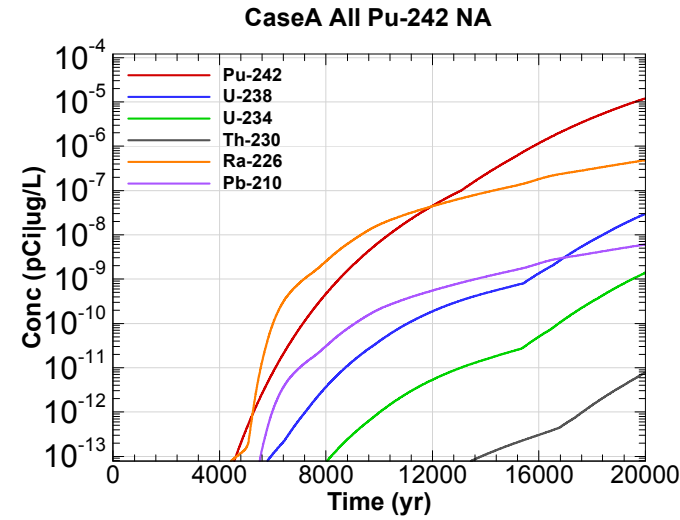

Figure B-56 - 100m Aquifer Concentration for CaseA All Pu-242 NA

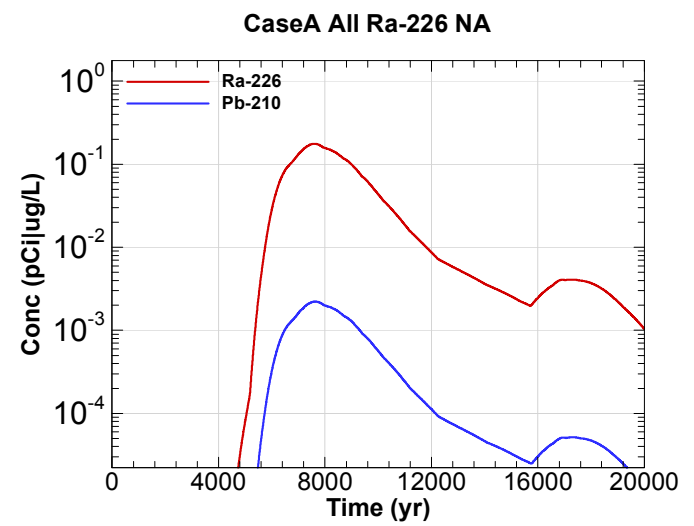

Figure B-58 - 100m Aquifer Concentration for CaseA All Ra-226 NA

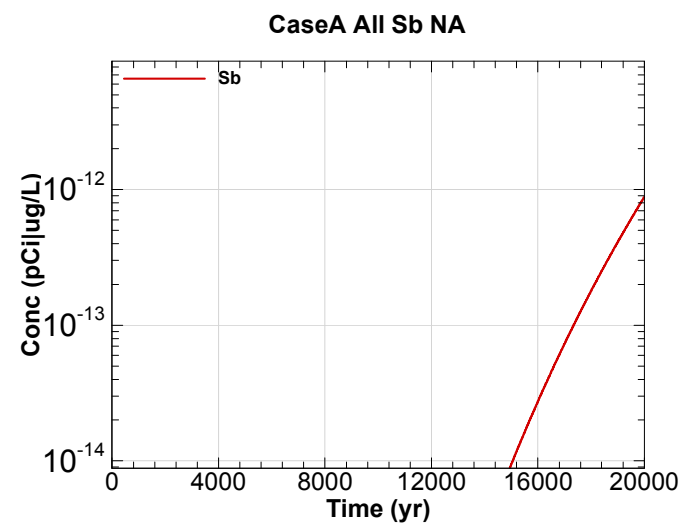

Figure B-60 - 100m Aquifer Concentration for CaseA All Sb NA 


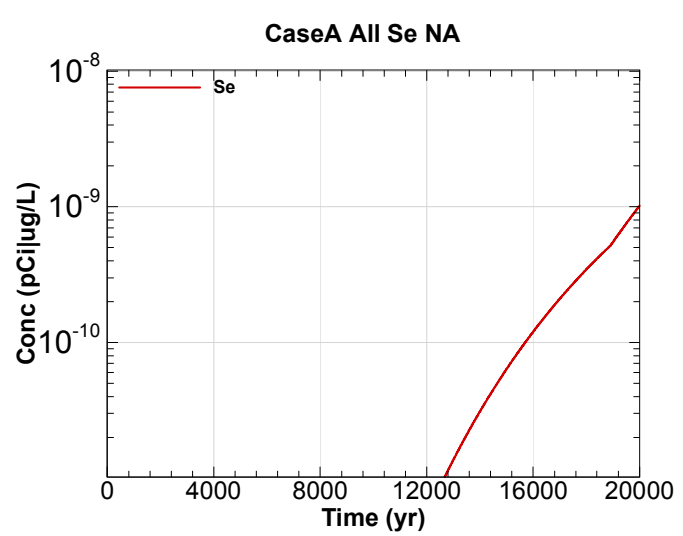

Figure B-61 - 100m Aquifer Concentration for CaseA All Se NA

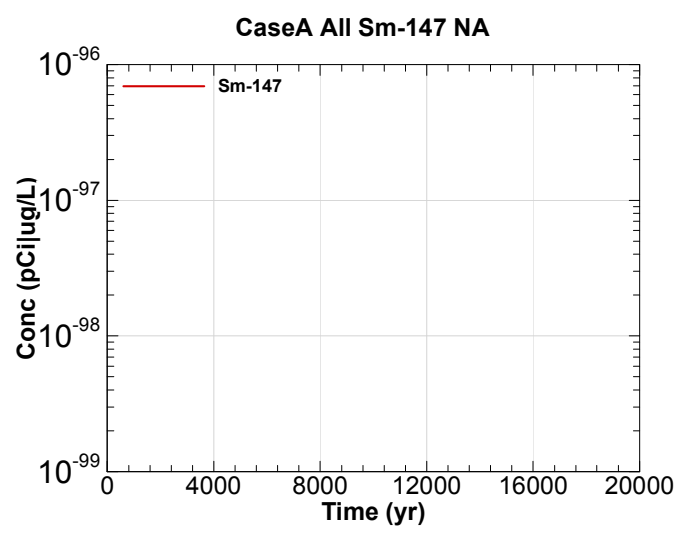

Figure B-63 - 100m Aquifer Concentration for CaseA All Sm-147 NA

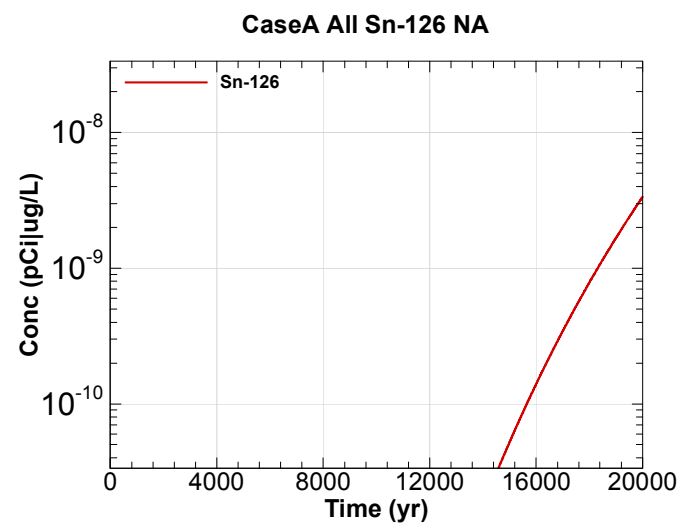

Figure B-65 - 100m Aquifer Concentration for CaseA All Sn-126 NA

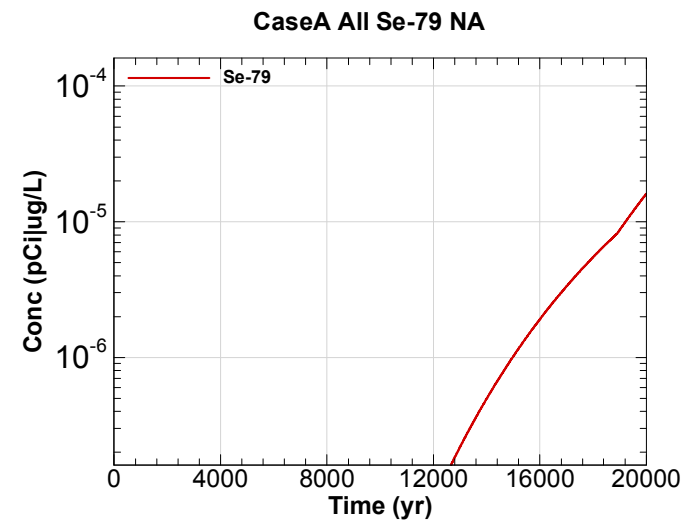

Figure B-62 - 100m Aquifer Concentration for CaseA All Se-79 NA

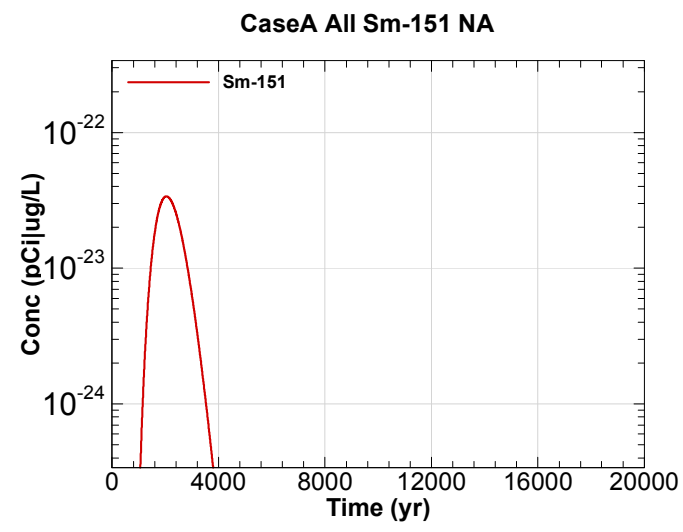

Figure B-64 - 100m Aquifer Concentration for CaseA All Sm-151 NA

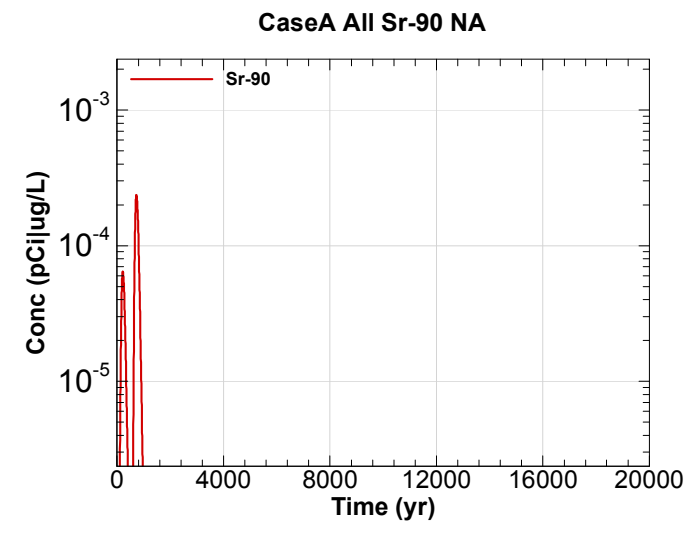

Figure B-66 - 100m Aquifer Concentration for CaseA All Sr-90 NA 


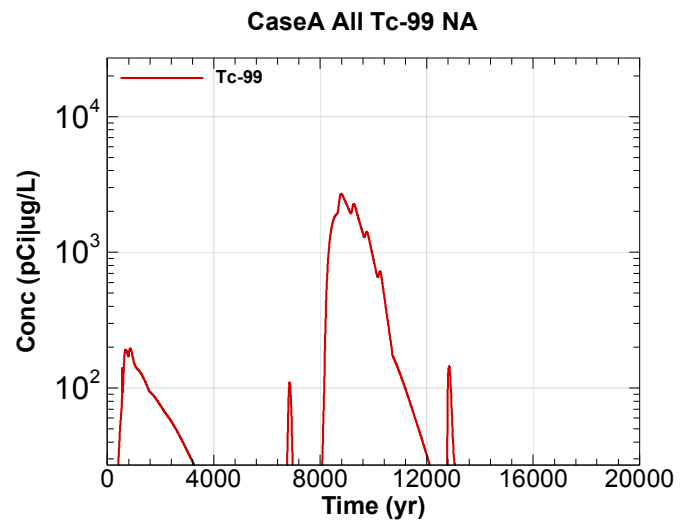

Figure B-67 - 100m Aquifer Concentration for CaseA All Tc-99 NA

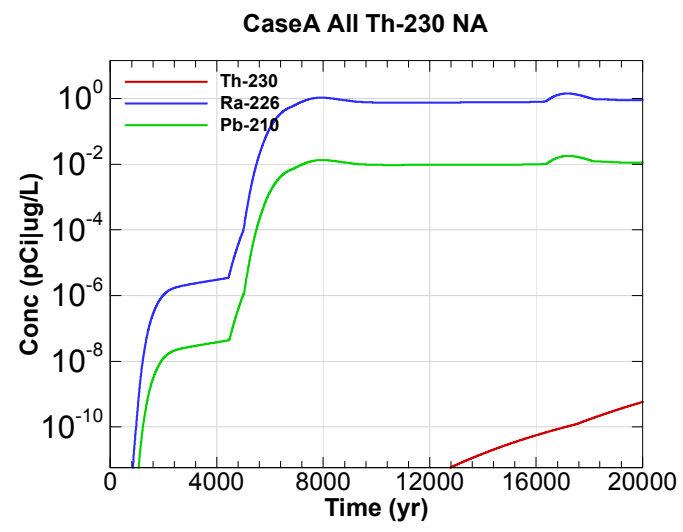

Figure B-69 - 100m Aquifer Concentration for CaseA All Th-230 NA

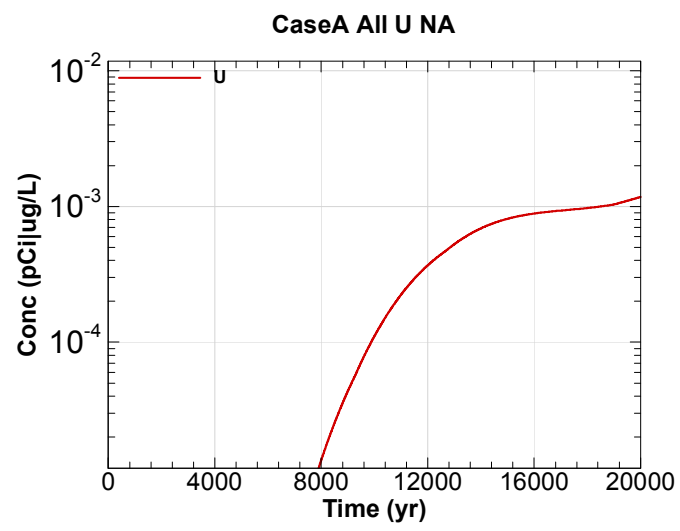

Figure B-71 - 100m Aquifer Concentration for CaseA All U NA

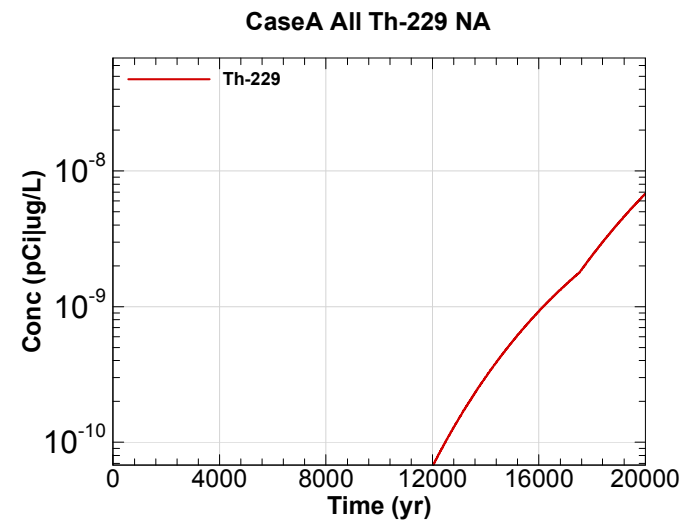

Figure B-68 - 100m Aquifer Concentration for CaseA All Th-229 NA

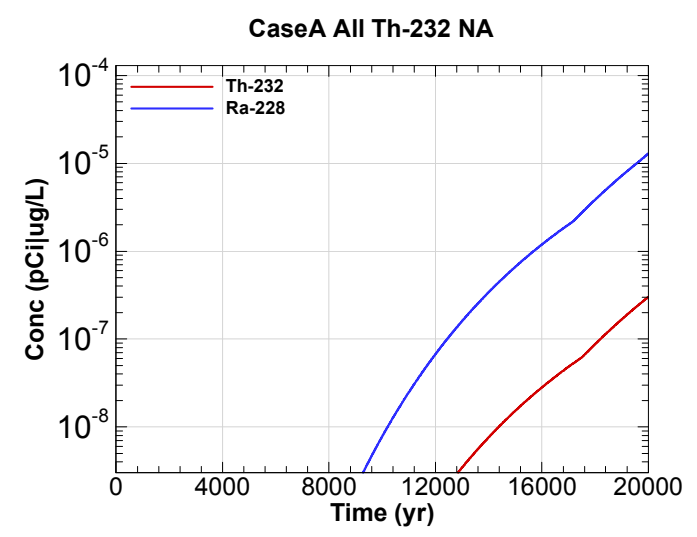

Figure B-70 - 100m Aquifer Concentration for CaseA All Th-232 NA

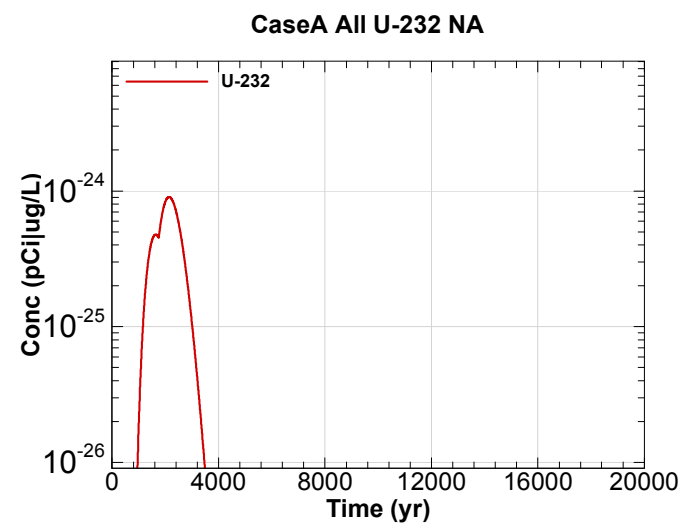

Figure B-72 - 100m Aquifer Concentration for CaseA All U-232 NA 


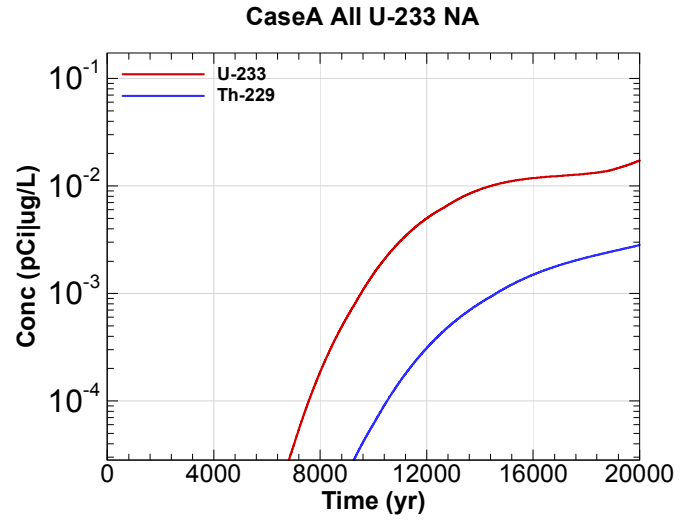

Figure B-73 - 100m Aquifer Concentration for CaseA All U-233 NA

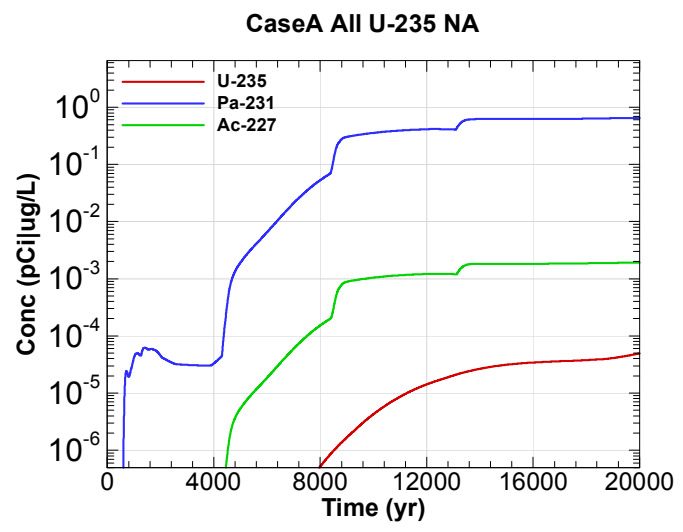

Figure B-75 - 100m Aquifer Concentration for CaseA All U-235 NA

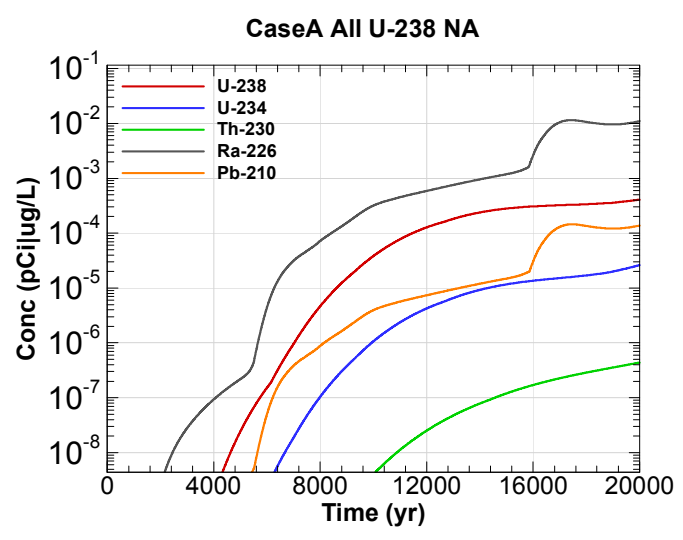

Figure B-77 - 100m Aquifer Concentration for CaseA All U-238 NA

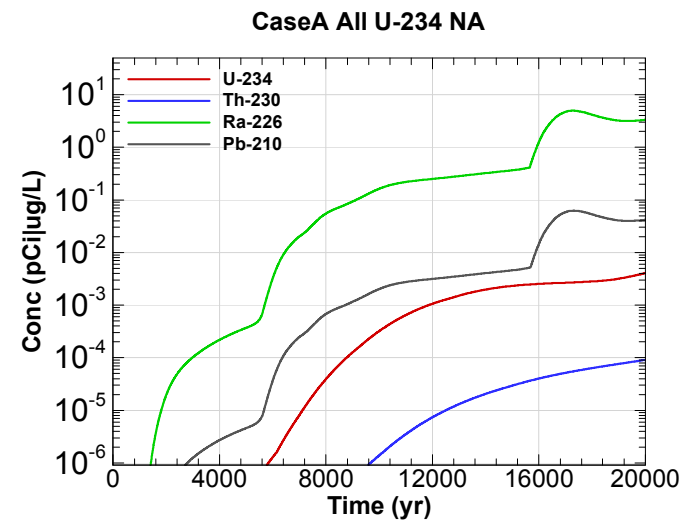

Figure B-74 - 100m Aquifer Concentration for CaseA All U-234 NA

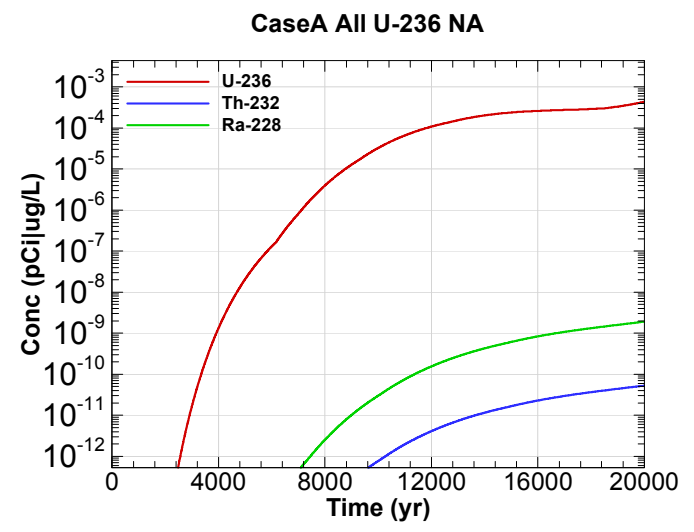

Figure B-76 - 100m Aquifer Concentration for CaseA All U-236 NA

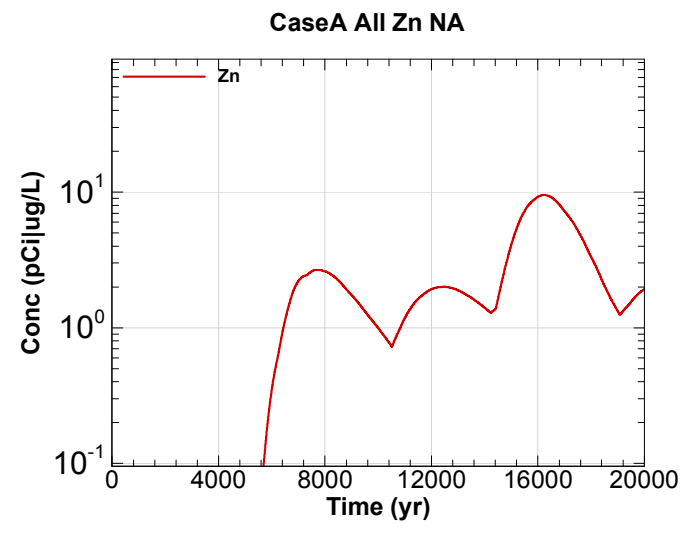

Figure B-78 - 100m Aquifer Concentration for CaseA All Zn NA 


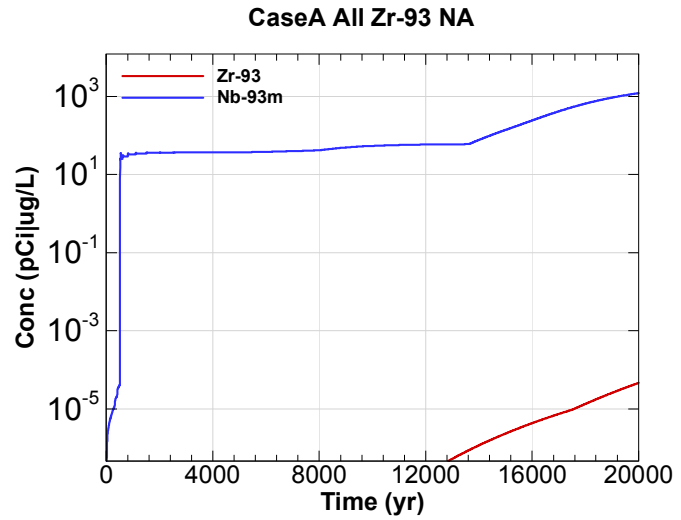

Figure B-79 - 100m Aquifer Concentration for CaseA All Zr-93 NA

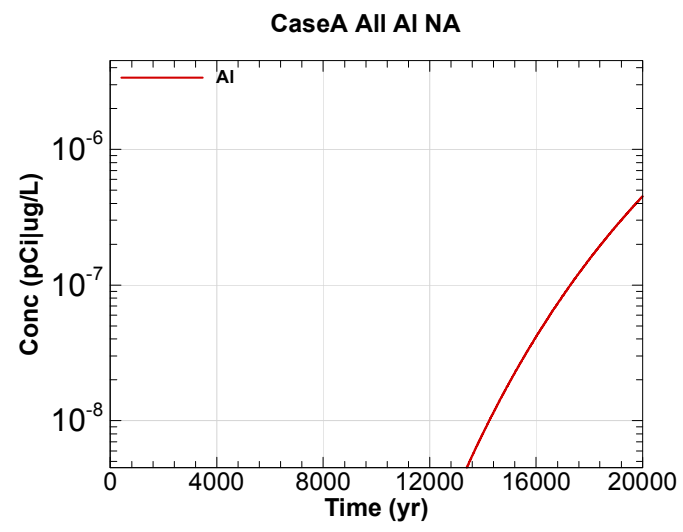

Figure B-81 - 100m Aquifer Concentration for CaseA All Al NA

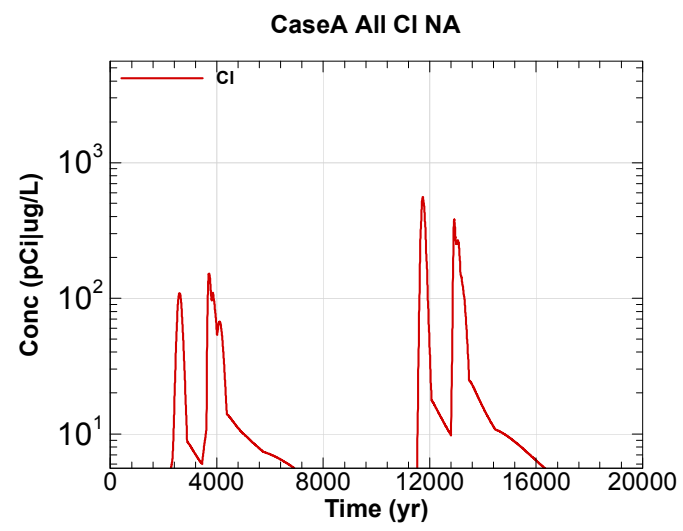

Figure B-83 - 100m Aquifer Concentration for CaseA All Cl NA

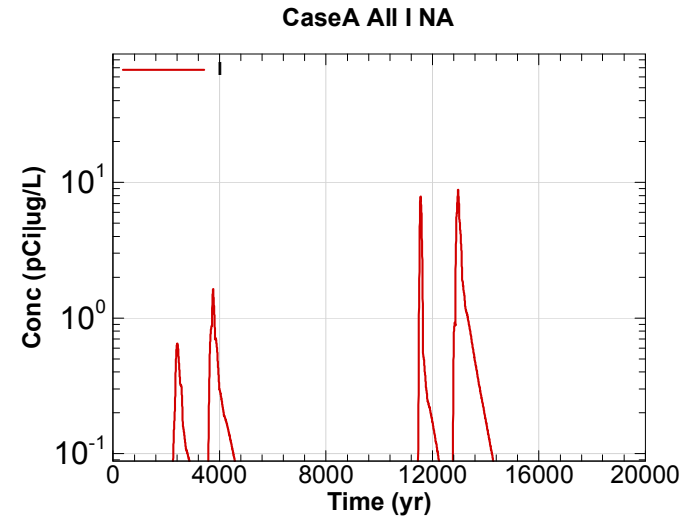

Figure B-80 - 100m Aquifer Concentration for CaseA All I NA

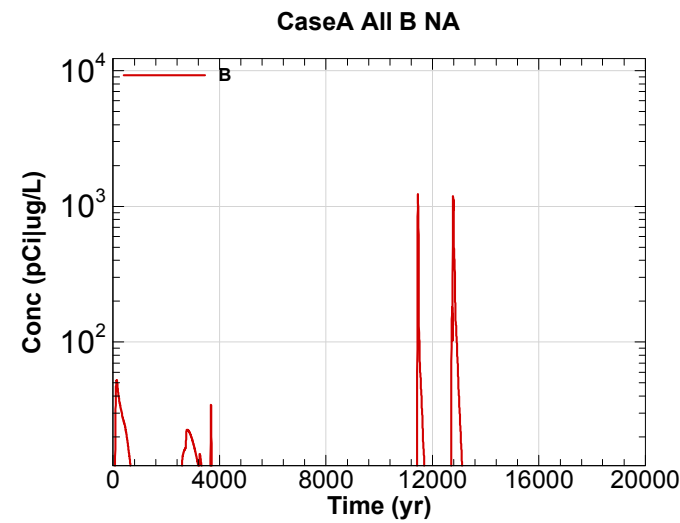

Figure B-82 - 100m Aquifer Concentration for CaseA All B NA

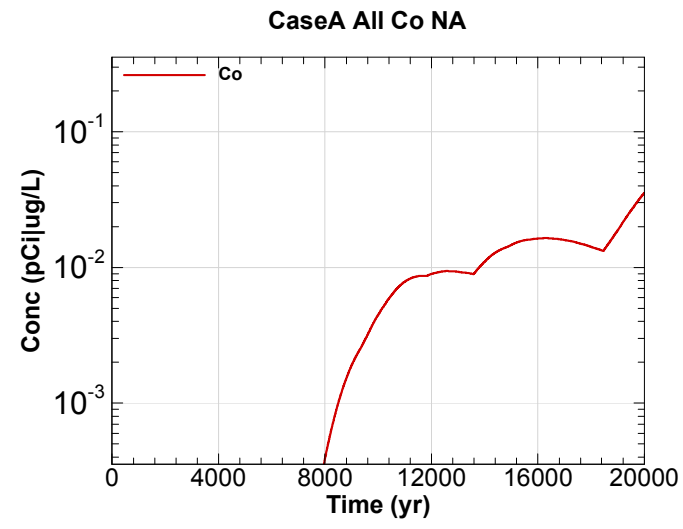

Figure B-84 - 100m Aquifer Concentration for CaseA All Co NA 


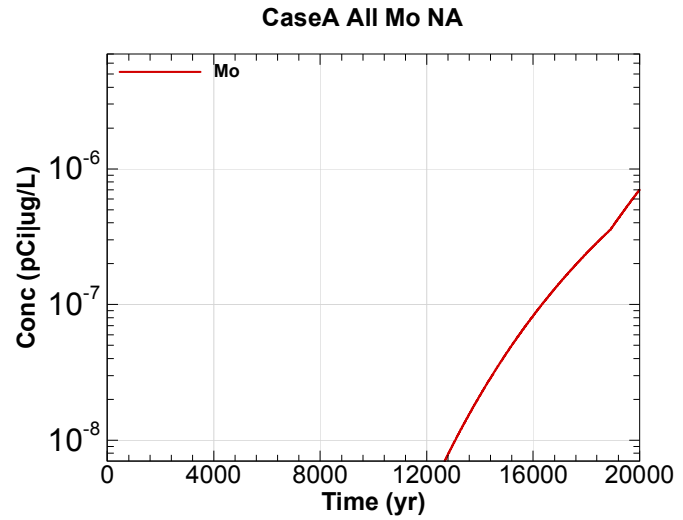

Figure B-85 - 100m Aquifer Concentration for CaseA All Mo NA

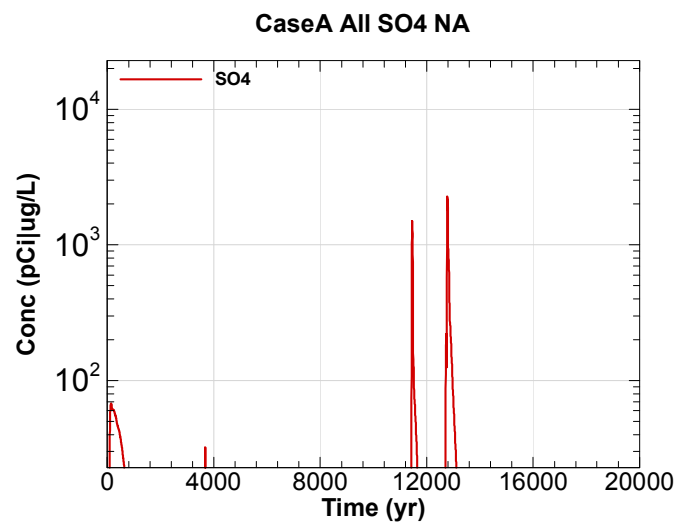

Figure B-87 - 100m Aquifer Concentration for CaseA All SO4 NA

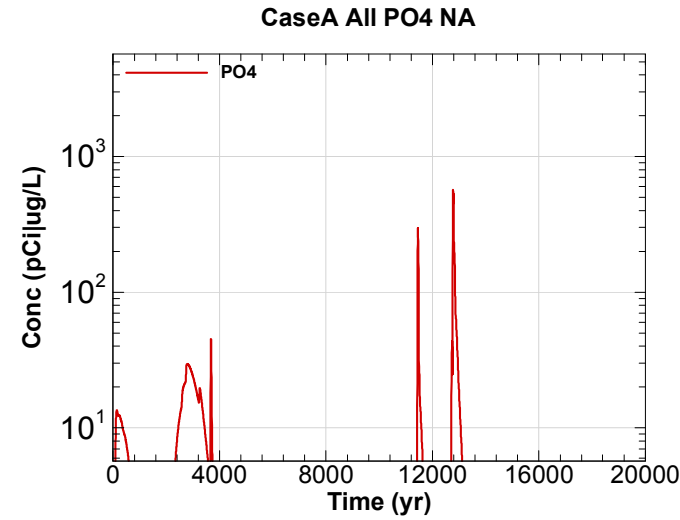

Figure B-86 - 100m Aquifer Concentration for CaseA All PO4 NA

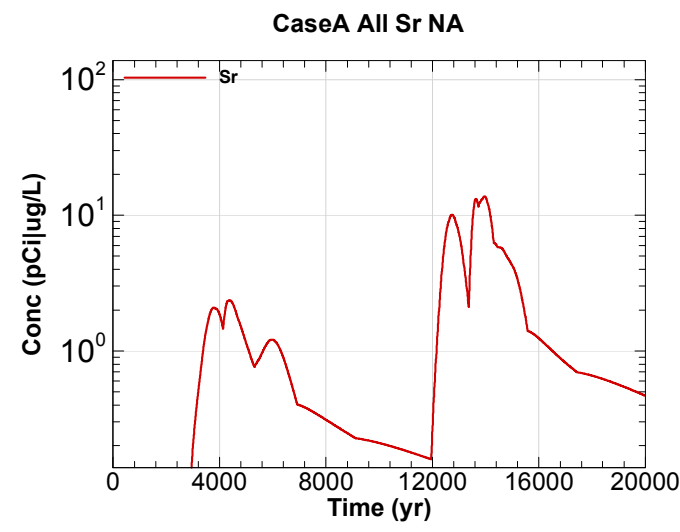

Figure B-88 - 100m Aquifer Concentration for CaseA All Sr NA 


\section{DISTRIBUTION:}

$\underline{\text { SRNS }}$

R. S. Aylward, 773-42A

H. H. Burns, 773-41A

D. A. Crowley, 774-43A

G. P. Flach, 773-42A

S. J. Hensel, 703-41A

T. Hang, 773-43A

J. M. Jordan, 703-41A

P. L. Lee, 703-41A

S. L. Marra, 773-A

C. Wilson (1 file copy \& 1 electronic copy), 773-43A - Rm. 213

SRR

T. W. Coffield, 705-1C

K. H. Rosenberger, 705-1C

S. Hommel, 705-1C

M. H. Layton, 705-1C

B. H. Lester, 705-1C

D. R. Watkins, 705-1C 